Article

\title{
Computational Simulation and Dimensioning of Solar-Combi Systems for Large-Size Sports Facilities: A Case Study for the Pancretan Stadium, Crete, Greece
}

\author{
Dimitris Al. Katsaprakakis 1
}

Power Plants Synthesis Laboratory, Department of Mechanical Engineering, Hellenic Mediterranean University, Estavromenos, 71410 Heraklion Crete, Greece; dkatsap@hmu.gr; Tel.: +30-2810-379220

Received: 21 February 2020; Accepted: 1 May 2020; Published: 5 May 2020

\begin{abstract}
The article examines the introduction of solar-combi systems in large-size sports facilities. The examined solar-combi systems consist of solar collectors, a biomass heater and thermal storage tanks. In a sense, they constitute hybrid thermal power plants. The full mathematical background is presented on the operation of such systems, along with a proposed operation algorithm, aiming at the maximization of the captured solar radiation. A case study is implemented for the coverage of the thermal energy needs for hot water production and swimming pools heating, met in the Pancretan Stadium, Crete, Greece. In this way, the article aims to indicate the technical and economic prerequisites that can guarantee the feasibility of the examined systems, highlighting the significant potential contribution of such systems towards the realization of energy transition plans from fossil fuels to renewables. The economic feasibility of the introduced system is based on the avoiding diesel oil and electricity procurement cost, consumed for the coverage of the thermal energy demands under consideration. The optimum dimensioning of the examined case study results to an annual thermal energy demand coverage balance of $55 \%$ by the solar collectors and $45 \%$ by the biomass heater, giving a payback period of 5-6 years.
\end{abstract}

Keywords: solar collectors; biomass heater; thermal storage; solar-combi systems; rational use of energy; energy performance upgrade

\section{Introduction}

\subsection{Thermal Energy Production from Renewables-The Case of Sports Facilities}

Heating needs are met in several different human activities, such as in the residential and commercial buildings, in sports facilities, in industrial processes, in agricultural applications etc. Although oil and coal still dominate the thermal energy production for all these uses, considerable research is executed on the introduction of alternative systems, aiming at the transition to Renewable Energy Sources (RES). These alternative systems are most commonly based on alternative solar collector types, combined heat and power units, geothermal heat exchangers and, recently, on the photovoltaic thermal hybrid solar collectors.

The most common solar collector types are uncovered solar collectors, flat plate solar collectors and vacuum tubes. Uncovered solar collectors are mainly employed for swimming pools heating in summer [1-3] and, in general, when relatively low final temperatures are required (below $30^{\circ} \mathrm{C}$ ). Unglazed solar collectors operating with reduced flow rates up to $75 \%$ can contribute to annual electricity savings of up to $80 \%$, with a reduction in the collectors' efficiency of only $10 \%$ [1]. They have been also proposed and dynamically simulated in combined operation with heat pumps, contributing to the increase in the Coefficient of Performance [2]. Finally, an international standard to determine the thermal performance of solar collectors is proposed in [3], including testing under unsteady conditions. 
Flat plate solar collectors are employed in domestic and commercial buildings for indoor space heating and hot water production $[4,5]$. Flat plate collectors have been studied widely with experimental approaches for domestic hot water production [4], indicating optimum flow rates between 5.3 and $6.5 \mathrm{~L} / \mathrm{min}$. A detailed review article on flat plate solar collectors is provided in [5], with presentation of different materials used to enhance the collector's efficiency (nanomaterials, polymers and phase changing materials to supply heat also during night) and techniques used to analyze the effect of various design parameters. Selective coating collectors have been proposed for applications with higher required temperatures, such as agricultural activities [6] or district heating systems, in combination with parabolic trough collectors [7]. It is shown that the final levelized cost for the supplied heat through a heating district system based on solar collectors in Denmark can be as low as $0.04 \mathrm{EUR} / \mathrm{kWh}$ th [7].

Vacuum tubes are employed for indoor space heating and hot water production in cold climates [8-12], as well as for industrial or agricultural applications, when high temperatures are required [13,14]. Particularly, a fundamental energy and exergy analysis is performed in [8] based both on a computational model and an experimental approach. It is found that the inlet temperature is the parameter that mostly affects the first and the second law efficiencies. Reviews on the available vacuum tube solar collectors are provided in [9,11], regarding their potential applications in residences, industries, desalination plants and power production plants, their mathematical modelling approaches and the accomplished research studies to improve both their efficiency and cost-effectiveness. Vacuum tubes solar collectors have been also simulated and studied purely for hot water production for the city of Sanandaj, Iran [10]. An integrative review and comparison study on the applications of flat plate and vacuum tubes solar collectors as constructive elements for buildings envelopes (Building-Integrated Solar Thermal systems) is presented in [12]. A new patented system of vacuum tubes collectors with a flat plate configuration is evaluated on economic and environmental criteria. Finally, vacuum tubes solar collectors have been proposed and studied for very special applications, such as the heating of greenhouses with the support of a heat pump [13] or as components of a passive solar desalination system [14].

Photovoltaic thermal hybrid solar collectors (PV/T) are utilized for both electricity and thermal power production. The thermal power captured by the heated photovoltaic panel is transferred to a network of pipelines adjusted on it, acting similarly with common flat plate solar collectors, cooling, at the same time, the photovoltaic panel and improving its efficiency. Detailed reviews on the advancements and the new technology trends on PV/T collectors is provided in $[15,16]$. Environmental life-cycle assessment of PV/T is executed in [17], showing that the life-cycle gas emissions of a PV/T collector are only $23 \%$ of a similar solar thermal collector and the solid wastes to the ground is only $35 \%$ of a single solar thermal collector.

Combined Heat and Power (CHP) cogeneration compact units are usually realized with a compact steam turbine or diesel generators of small size. A CHP plant for power, heating and cooling production is studied in [18] for a high-rise building in Shangai, through the computational simulation of its operation, with and without the support of thermal energy storage, proving its economic feasibility, compared to conventional indoor space conditioning technologies. A review on the recent integrations of micro CHP plants proposed for residential buildings has been accomplished and presented in [19]. Finally, a comparative study of two biomass fueled CHP plants of small size is accomplished and presented in [20], concluding in annual overall efficiencies at the range of $76-81 \%$ and breakeven electricity selling price between 0.087 and $0.097 \mathrm{GBP} / \mathrm{kWh}$ el

Geothermal heat exchangers (GHE) are also utilized for indoor space heating and cooling. These systems feature as a highly attractive option, due to their potential utilization for both heating and cooling production, exhibiting several comparative benefits with regard to conventional air-to-air heat pumps [21], implemented for either residential and commercial buildings, via horizontal or vertical layouts [22], or for large office buildings, mainly through vertical GHE installed in boreholes [23]. 
In warm climates, integrated solar collectors and thermal storage tanks systems supported by a conventional heat source can guaranteed high solar energy penetration for indoor space heating loads, hot water production, etc. These systems are often referred to as "solar-combi systems" and will be thoroughly presented in Section 3.

Heating needs in sports facilities are mainly met for the indoor space conditioning, the swimming pools heating and the production of hot water. In most cases, these thermal energy needs are traditionally covered by fossil fuels (diesel oil) and electricity. So far, relatively limited work has been published in the scientific literature on the utilization of RES for thermal power production in sports facilities. In [24] the retrofit of a solar thermal field is studied for a sport center in Majorca, resulting to annual energy saving of $14 \%$ and annual monetary saving of $30 \%$. The energy performance upgrade of another sport center in Dubai, UAE is studied in [25], proposing electricity and thermal energy production hydrogen technologies. Most relevant articles, however, mainly focus on swimming pools heating. In these articles we can have comparative analyses of different heating alternative technologies (biomass heaters, solar systems, GHE, etc.) [26,27]. The results of these articles show high economic feasibility of all the examined systems, compared to the consumption of oil for the pools' heating, with payback periods at the range of 2 to 3 years. Furthermore, particular systems have been applied for specific cases of swimming pools, studied and optimized as case studies, such as a hybrid thermal energy system based on solar collectors for the heating of a swimming pool in Algeria [28], a solar-assisted heat pump studied for six different locations in Brazil and in Chile [29] and a geothermal heat exchanger system for a swimming pool in Napoli, Italy [30].

This article aims to cover this literature gap with regard to the use of RES technologies for heating production in sports facilities, proving their economic and technical feasibility.

\subsection{Scope of the Article-Points of Originality}

This article presents the overall process for the simulation and the dimensioning of solar-combi systems. The study is focused particularly on the introduction of these systems in sports facilities of large size. It is realized through a case study for the Pancretan Stadium, Crete, Greece-accomplished in the frame of the overall energy performance upgrade of the stadium [31]. More specifically, the presented topics in this article are:

- The methodology adopted for the solar-combi system's dimensioning and dynamic simulation;

- Full presentation of the mathematical background;

- Economic analysis of the introduced system and economic feasibility evaluation.

The above topics also constitute the essential innovation features of the present article. Essential information on the dynamic simulation approach, the operation algorithm and on the technical aspects of the examined system are for first time introduced in the scientific literature. The dimensioning methodology is for first time gathered and presented as a whole. Additionally, following the accomplished literature survey, no relevant article was found with the realization of the dimensioning process, based on the computational simulation of the system's annual operation, using annual time series of average hourly values.

All these innovative elements are applied and validated in a demanding and complex case study, which refers to the combined thermal energy coverage for both hot water production and swimming pools heating in a large size sports facility, the Pancretan Stadium, in Crete, Greece. With the application of the introduced methodology, the article highlights the technical and economic prerequisites which can ensure the feasibility of solar-combi systems. It aims to constitute a reference case-study on the simulation and dimensioning of these systems. 


\section{Existing Situation}

\subsection{The Pancretan Stadium}

The location of the Pancretan Stadium is found at the western side of Heraklion, Crete, Greece, next to the coastline, as shown in Figure $1\left(35^{\circ} 20^{\prime} 12^{\prime \prime} \mathrm{N}, 25^{\circ} 6^{\prime} 22^{\prime \prime} \mathrm{E}\right)$, with a total area of $184,000 \mathrm{~m}^{2}$ (red line in Figure 1). The main stadium's capacity is 26,240 spectators.

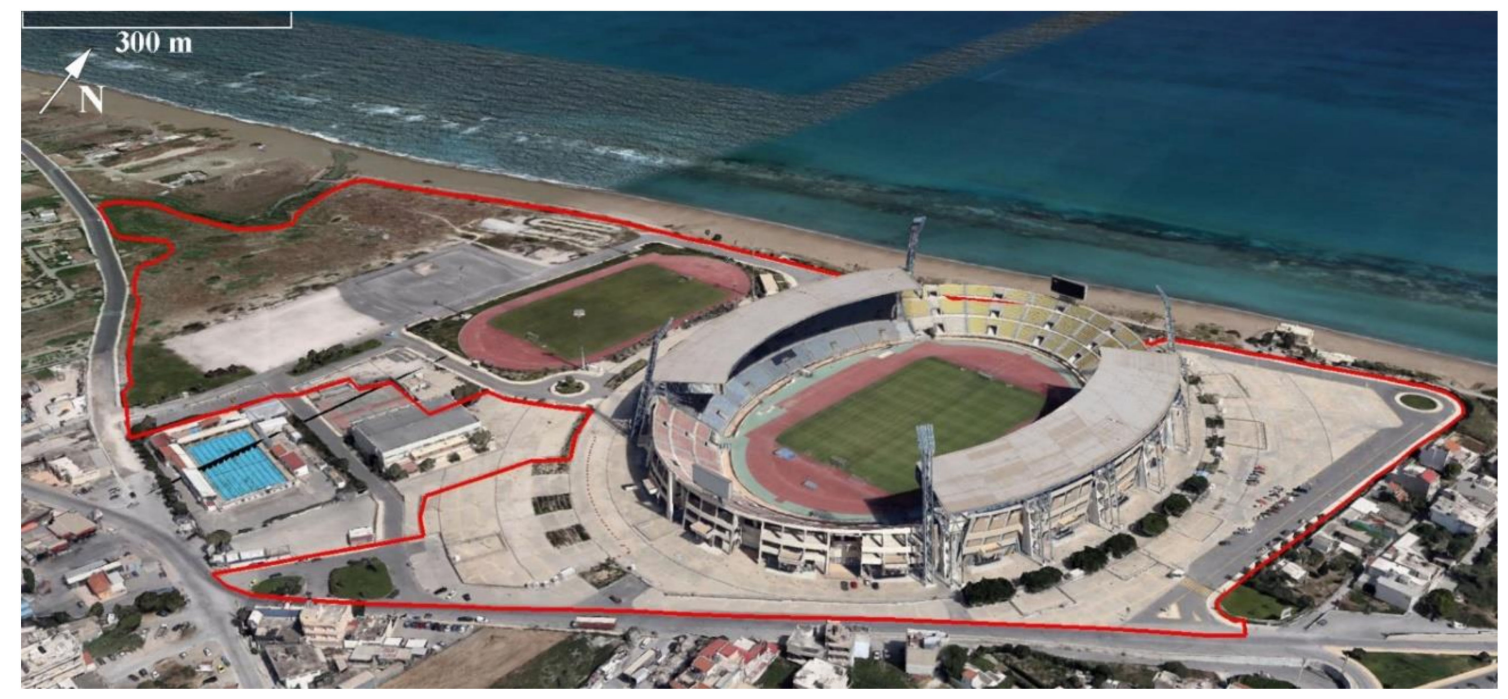

Figure 1. 3D representation of the Pancretan Stadium and the auxiliary outdoor space from southeast.

Below the main stadium's stands, more than 25 sports halls are hosted, including two swimming pools, supported by changing rooms, offices and stock rooms, covering a total area of $19,397 \mathrm{~m}^{2}$. All these facilities are used on a daily basis (apart from Sundays) to host a variety of sports activities implemented by the local municipality or local sports clubs.

\subsection{Existing Thermal Energy Consumption for Hot Water Production}

Hot water is exclusively consumed in the stadium's changing rooms. The corresponding annual thermal energy consumption is estimated given the assumptions and the data provided by the stadium's management:

- The stadium's facilities are used by 900 users daily; half of them make use of the changing rooms and consume $20 \mathrm{~L}$ of hot water.

- The daily swimming pools users are estimated at 500; each one of them consumes $30 \mathrm{~L}$ of hot water.

- Adopted hot water properties: temperature $T_{h w}=45^{\circ} \mathrm{C}$, density $\rho_{h w}=990 \mathrm{~kg} / \mathrm{m}^{3}$ and specific heat capacity $4.180 \mathrm{~J} / \mathrm{kg} \cdot \mathrm{K}$.

- A 24-h thermal power demand profile is developed by applying the following relationship on hourly basis:

$$
Q_{h w}=m_{h w} \cdot c_{w} \cdot \Delta T=m_{h w} \cdot c_{w} \cdot\left(T_{h w}-T_{w s}\right),
$$

where:

$Q_{h w}: \quad$ the thermal power required for hot water production (in $\mathrm{kW}$ );

$m_{h w}: \quad$ the consumed hot water mass flow rate, equal to the

$T_{\text {ws }}$ : the water temperature in the water supply network. 
The water supply temperature was retrieved for the region of Crete by the Greek Directive on Buildings' Energy Performance Assessment [32]. These data, with the calculated thermal energy required for hot water production, are presented in Table 1.

Table 1. Monthly thermal energy required for hot water production in the Pancretan Stadium.

\begin{tabular}{cccccc}
\hline Month & $\begin{array}{c}\text { Water } \\
\text { Temperature in } \\
\text { Supply Network } \\
\left({ }^{\circ} \mathbf{C}\right)\end{array}$ & $\begin{array}{c}\text { Monthly Final } \\
\text { Thermal Energy } \\
\text { Consumption } \\
\mathbf{( k W h )}\end{array}$ & Month & $\begin{array}{c}\text { Water } \\
\text { Temperature in } \\
\text { Supply Network } \\
\left({ }^{\circ} \mathbf{C}\right)\end{array}$ & $\begin{array}{c}\text { Monthly Final } \\
\text { Thermal Energy } \\
\text { Consumption } \\
\mathbf{( k W h )}\end{array}$ \\
\hline 1 & 13 & 27,670 & 7 & 26.2 & 16,256 \\
2 & 12.8 & 25,149 & 8 & 26.6 & 15,910 \\
3 & 13.8 & 26,978 & 9 & 24.9 & 16,819 \\
4 & 16.3 & 24,016 & 10 & 21.7 & 20,147 \\
5 & 19.9 & 21,704 & 11 & 18.1 & 22,509 \\
6 & 23.8 & 17,740 & 12 & 14.8 & 26,113 \\
\hline
\end{tabular}

The annual final thermal energy consumption is calculated at $261,015 \mathrm{kWh}$, by adding the monthly values in Table 1. Given the above assumptions and facts, one thermal power consumption daily profile for hot water production is developed for each different month. Four of them are presented in Figure 2. The corresponding thermal power demand annual time series, presented in Figure 3, is developed by consecutively replicating these daily profiles day by day for the whole annual period. Figure 3 is designed by applying a linear interpolation between the average monthly water temperatures in the supply network.

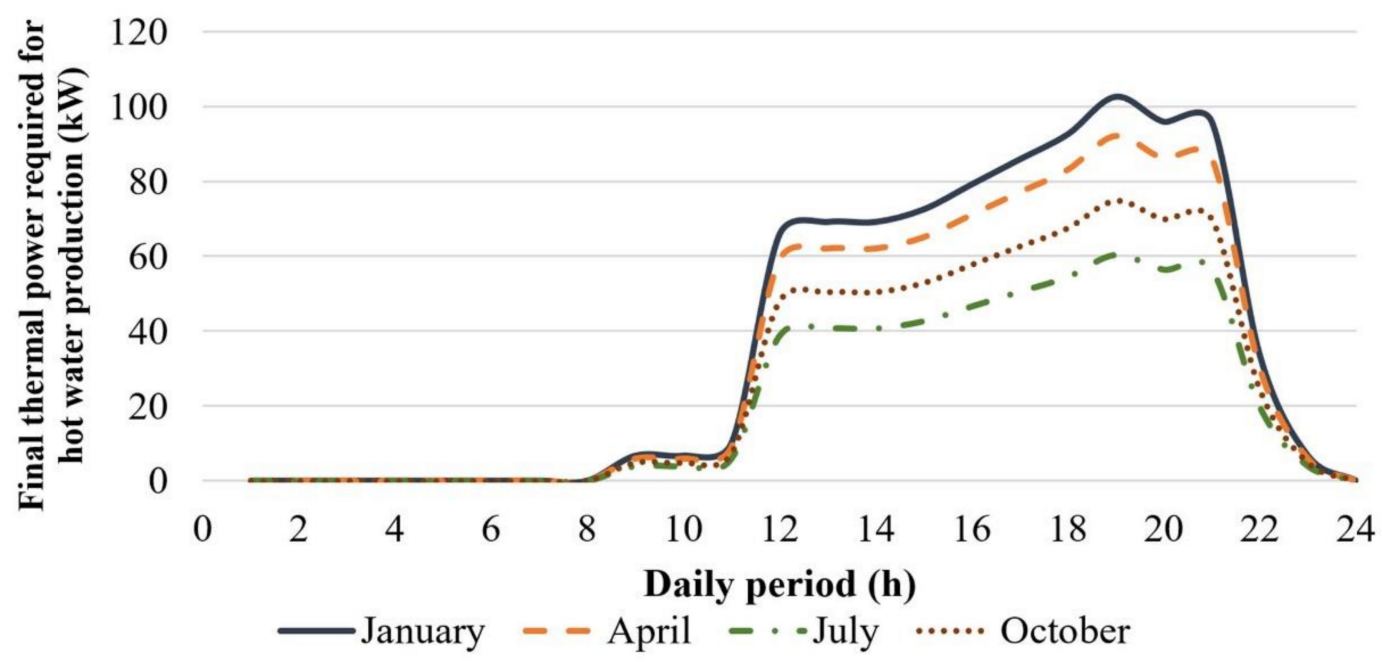

Figure 2. Thermal power consumption daily profile for hot water production for four characteristic months. 


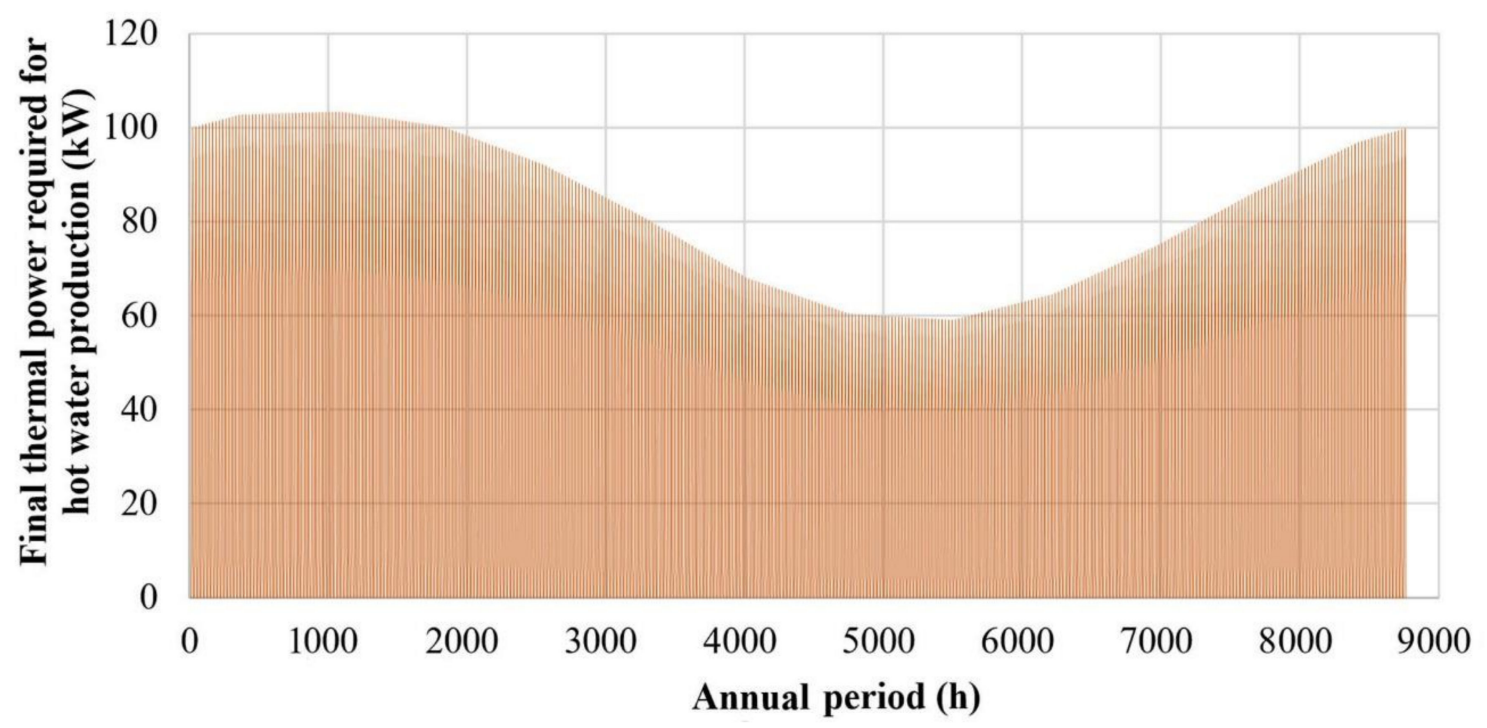

Figure 3. Thermal power consumption annual time series for hot water production.

\subsection{Existing Thermal Energy Consumption for Swimming Pools Heating}

A main and a training swimming pool are hosted in the stadium's indoor space facilities. The calculation of the thermal energy required for the swimming pools heating starts with the calculation of the indoor space heating loads. In this first stage, the climate conditions and the qualitative constructive features of the stadium's envelope are involved [33,34]. The following values were adopted for the thermal comfort conditions and the air ventilation requirements [32]:

- Temperature: $18{ }^{\circ} \mathrm{C}$ in winter and $25^{\circ} \mathrm{C}$ in summer;

- Relative humidity: $50 \%$;

- Required ventilation: $33.75 \mathrm{~m}^{3}$ of fresh air per hour and $\mathrm{m}^{2}$ of indoor covered space.

The indoor space heating and cooling loads calculation is executed on the assumption that the above thermal comfort conditions and air ventilation requirements are fulfilled. The process was applied with TRNSYS. Among the results, the annual fluctuation of the indoor space temperature is obtained [31]. With the indoor space temperature $T_{\text {in }}$ annual fluctuation known, the following general relationship is applied for the swimming pools heating loads $Q_{s p}$ calculation:

$$
Q_{s p}=A_{s p} \cdot U \cdot\left(T_{w}-T_{i n}\right),
$$

where:

$A_{s p}: \quad$ the swimming pools upper surface (in $\mathrm{m}^{2}$ );

$U$ : $\quad$ the U-factor determining the heat losses rate from the swimming pools' surface to the indoor environment (in $\mathrm{W} / \mathrm{m}^{2} \cdot \mathrm{K}$ );

$T_{w}$ : $\quad$ the water temperature in the swimming pools (see Table 2).

The U-factor refers to the heat transfer rate directly from the swimming pool's upper surface to the indoor environment, hence it is given by the relationship:

$$
U=h_{r w}+h_{c}
$$

where $h_{c}$ is the convective heat transfer factor for indoor space air which flows above horizontal surfaces [33,34] (see Table 2), and $h_{r w}$ is the heat transfer factor with radiation, given by the following relationship:

$$
h_{r w}=4 \cdot \varepsilon_{w} \cdot \sigma \cdot\left(\frac{T_{w}+T_{i n}}{2}\right)^{3}
$$


where $\varepsilon_{w}$ is the radiation emissivity of water and $\sigma$ is the Stefan-Boltzman constant (see Table 2 and the nomenclature table). The ratio inside the parenthesis in relationship (4) is the average water and indoor space temperature.

Table 2. Calculation parameters for the swimming pool's heating loads calculation in the existing and the proposed operation.

\begin{tabular}{cc}
\hline Parameter & Value \\
\hline Radiation emissivity of water $\varepsilon_{w}$ & 0.957 \\
Radiation emissivity of the insulating floating cover material $\varepsilon_{\mathcal{c}}$ & 0.550 \\
space $\left(\mathrm{W} / \mathrm{m}^{2} \cdot \mathrm{K}\right)[33,34]$ & 2.5 \\
Convective coefficient $h_{c}$ for heat transfer from horizontal indoor surface to the indoor & 50.0 \\
Convective coefficient $h_{w}$ of standing still water $\left(\mathrm{W} / \mathrm{m}^{2} \cdot \mathrm{K}\right)[33,34]$ & 2.0 \\
Insulating cover thickness $d_{c}(\mathrm{~cm})$ & 0.025 \\
Insulating cover conductivity coefficient $k_{c}(\mathrm{~W} / \mathrm{m} \cdot \mathrm{K})$ & $25 \times 12.5=312.5$ \\
Main swimming pool's upper surface dimensions $\left(\mathrm{m}^{2}\right)$ & $12.5 \times 6=75$ \\
Training swimming pool's upper surface dimensions $\left(\mathrm{m}^{2}\right)$ & $26 / 30$ \\
Daily operation schedule $($ Monday-Friday) & $14: 00-22: 00$ \\
Saturday operation schedule & $9: 00-14: 00$ \\
\hline
\end{tabular}

In Figure 4, the annual fluctuation of the final thermal power required for the swimming pools heating is presented. The corresponding annual thermal energy is calculated at $112,216 \mathrm{kWh}$.

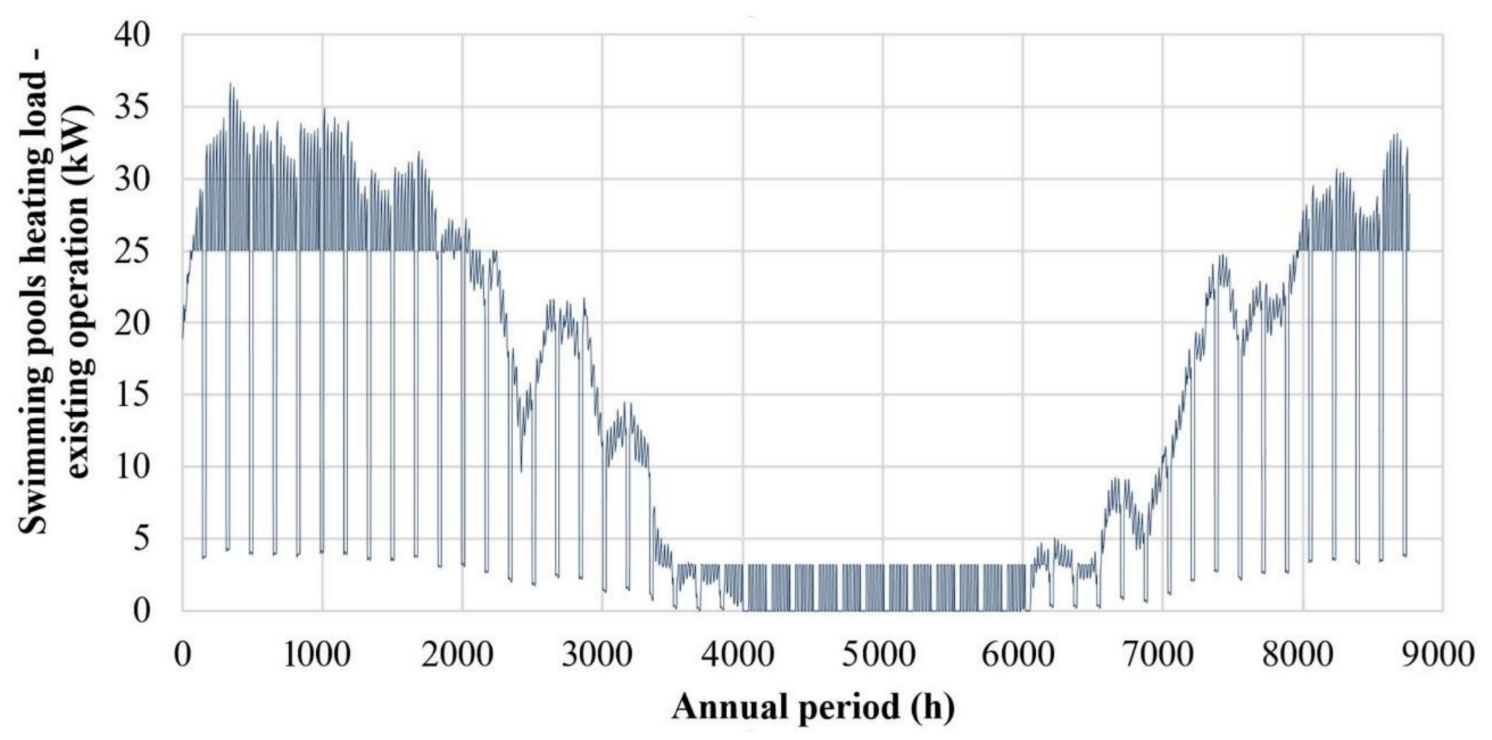

Figure 4. Annual fluctuation of the final thermal power required for the swimming pools heating.

\subsection{Existing Primary Energy Consumption}

According to the stadium's management, 16,500 L of diesel oil were consumed both in 2016 and 2017 exclusively for hot water production. The relevant available infrastructure in the stadium consists of one diesel oil burner and four thermal storage tanks, each one of them connected to the oil burner and equipped with 12 electrical resistances of $3 \mathrm{~kW}$ each ( $36 \mathrm{~kW}$ in each thermal tank). The total efficiency of the existing diesel oil burner and the heating distribution network are found at $80 \%$ and $95 \%$, respectively, in the issued energy audit report. Adopting the diesel oil specific heat capacity at $10.25 \mathrm{kWh} / \mathrm{L}$ [32], the final thermal energy that corresponds to the annual diesel oil existing consumption is calculated as shown below:

$$
16,500 \mathrm{~L} \times 10.25 \mathrm{kWh} / \mathrm{L} \times 0.80 \times 0.95=128,550 \mathrm{kWh}
$$


The remaining final thermal energy required annually for hot water production is sensibly covered by the available electrical resistances, imposing an annual electricity consumption calculated as shown below, also accounting for the heating distribution network efficiency (95\%):

$$
(261,015-128,550) \mathrm{kWh} / 0.95=139,436 \mathrm{kWh} .
$$

With regard to the swimming pools heating in the current operation state this is fulfilled by two air-to-air heat pumps. The required electricity consumption is simply calculated by introducing a typical Coefficient of Performance (COP) curve (Figure 5) versus the outdoor ambient temperature. The annual power consumption fluctuation for the swimming pools heating is presented in Figure 6.

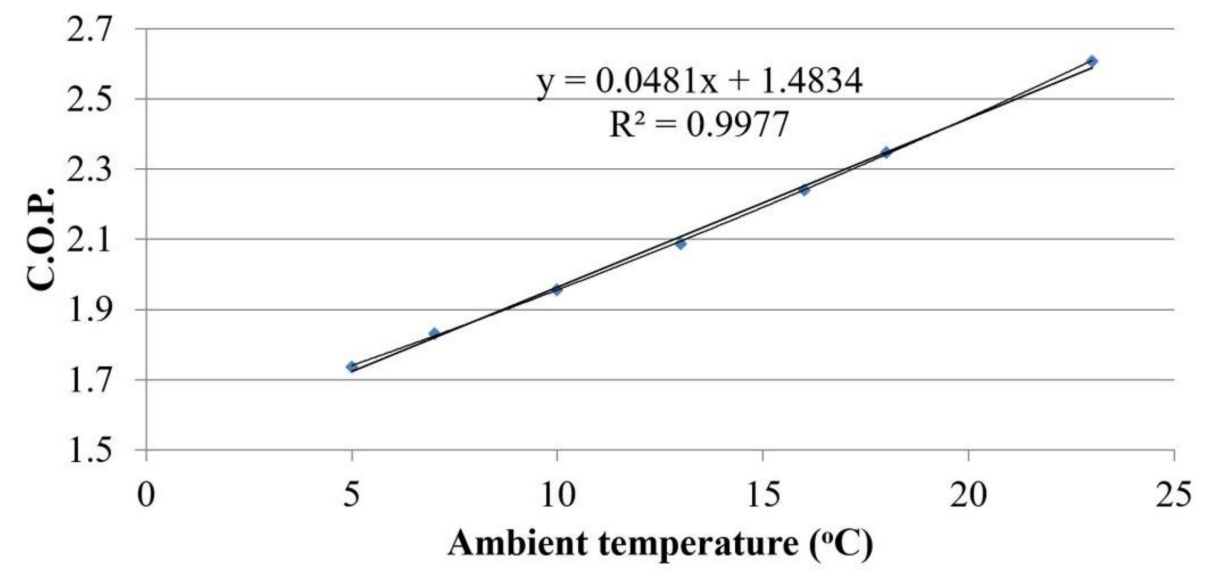

Figure 5. Typical COP fluctuation curve versus the ambient outdoor temperature for the existing air-to-air heat pumps employed for the swimming pools heating.

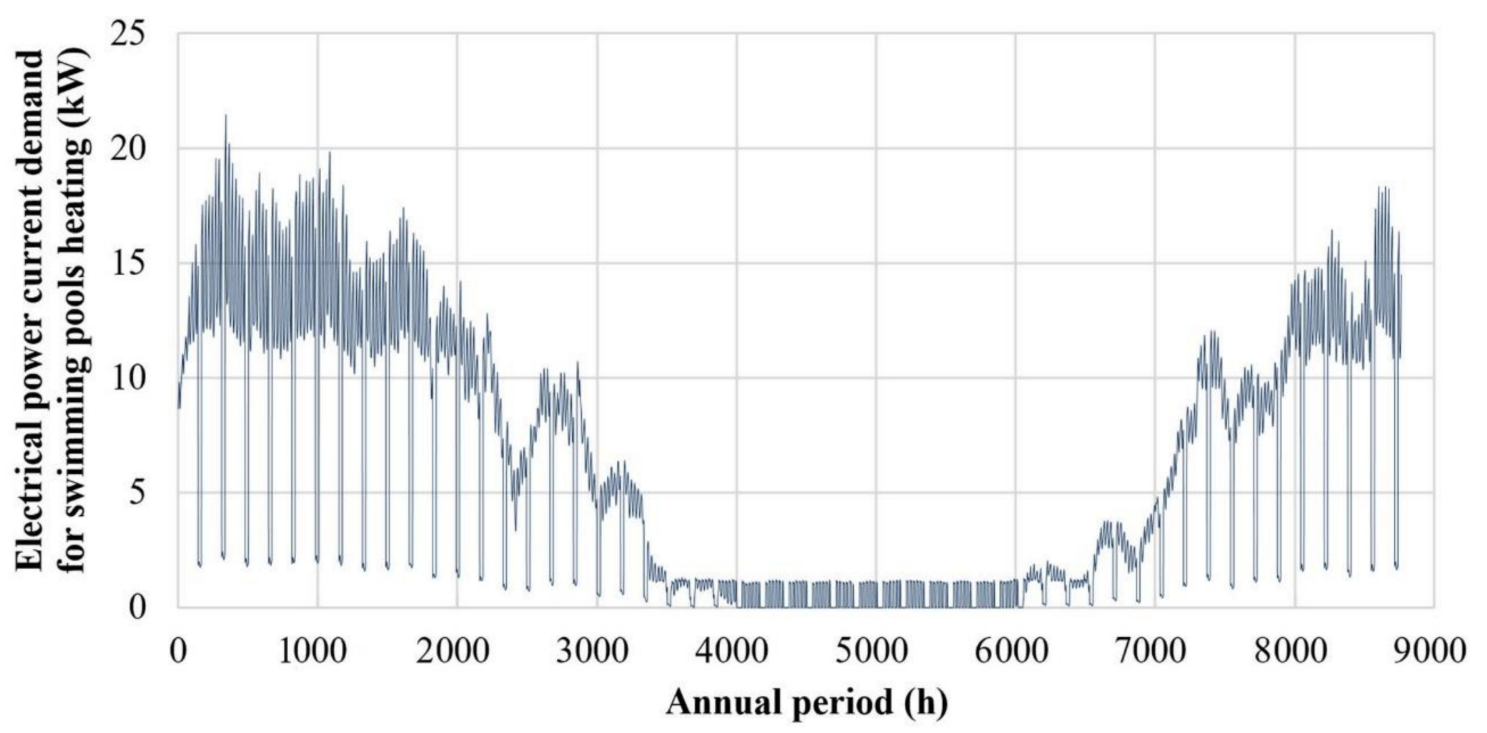

Figure 6. Annual fluctuation of electricity demand for the swimming pools heating in the existing operation.

The results from the above calculations are summarized in Table 3, introducing also the corresponding primary energy consumptions, calculated by multiplying [32]:

- $\quad$ The chemical energy contained in the consumed diesel oil with a factor of 1.1;

- The electricity consumption with a factor of 2.9, in case it is produced by thermal power plants. 
Table 3. Annual thermal and primary energy consumption for the production of hot water and the swimming pools heating in the existing operation of the Pancretan Stadium.

\begin{tabular}{|c|c|c|c|c|}
\hline \multicolumn{2}{|c|}{ Heating Load } & Hot Water Production & Swimming Pools Heating & Total \\
\hline \multicolumn{2}{|c|}{ Thermal energy demand (kWh) } & 261,015 & 112,216 & 373,231 \\
\hline \multirow{2}{*}{$\begin{array}{l}\text { Thermal energy } \\
\text { production }(\mathrm{kWh})\end{array}$} & Diesel oil & 128,550 & 0 & 128,550 \\
\hline & Electricity & 132,465 & 112,216 & 244,681 \\
\hline \multirow{2}{*}{$\begin{array}{l}\text { Energy source } \\
\text { consumption }\end{array}$} & Diesel oil (L) & 16,500 & 0 & 16,500 \\
\hline & Electricity (kWh) & 139,436 & 52,198 & 191,634 \\
\hline \multirow{3}{*}{$\begin{array}{c}\text { Primary energy } \\
\text { consumption } \\
(\mathrm{kWh})\end{array}$} & Diesel oil & 186,059 & 0 & 186,059 \\
\hline & Electricity & 404,366 & 151,373 & 555,739 \\
\hline & Total & 590,425 & 151,373 & 741,798 \\
\hline
\end{tabular}

Finally, Table 4 presents the total annual diesel oil and electricity procurement cost for hot water production and swimming pools heating in the stadium, given the diesel oil and electricity procurement prices in Crete in 2016.

Table 4. Analysis of the energy resources existing procurement cost for hot water production and swimming pools heating.

\begin{tabular}{cccc}
\hline Energy Source/Use & Consumption & Procurement Price & Total Procurement Cost (EUR) \\
\hline Diesel oil/hot water production & $16,500 \mathrm{~L}$ & $1 \mathrm{EUR} / \mathrm{L}$ & 16,500 \\
Electricity/hot water production & $139,436 \mathrm{kWh}$ & $0.1729 \mathrm{EUR} / \mathrm{kWh}$ & 24,108 \\
Electricity/swimming pools heating & $52,198 \mathrm{kWh}$ & $0.1729 \mathrm{UR} / \mathrm{kWh}$ & 9025 \\
Existing energy resources total procurement cost (EUR) & 49,634 \\
\hline
\end{tabular}

\section{Solar-Combi Systems}

In Figure 7, the essential layout of a solar-combi system is presented [35], consisting of solar collectors, thermal energy storage units and a back-up unit. The operation algorithm of a solar-combi system is realized by a control unit, according to the specific use and the demand requirements of each different application [35]. Solar-combi systems are most commonly introduced for indoor space heating for residential buildings [36-40], schools [41] and hotels [42], for swimming pool heating [29,43], even for central heating district systems [44] and for advanced systems for both pure and hot water production [45]. The most usually investigated topics on solar-combi systems are:

- Computational simulation, realizing alternative operation algorithms [46,47];

- Performance evaluation, comparing computational and experimental results [48];

- Validation of alternative thermal storage technologies, such as solid materials, water thermal tanks and phase change materials [49,50];

- Performance evaluation with seasonal thermal storage $[38,51,52]$ or under different operation conditions [53].

In this article, solar-combi systems are investigated through a case study accomplished for the above presented final thermal energy needs coverage, met in the Pancretan Stadium. A biomass heater is proposed as the back-up unit, given the availability of abundant solid biomass in Crete, mainly from the olive trees pruning. Selective coating solar collectors are utilized as RES units and water thermal storage tanks will be used as thermal storage units.

Solar-combi systems should be considered as the optimum technology in the examined case, for a number of reasons, starting from the high available solar radiation in the Mediterranean region, even during the winter period, as documented in Section 4.1. 


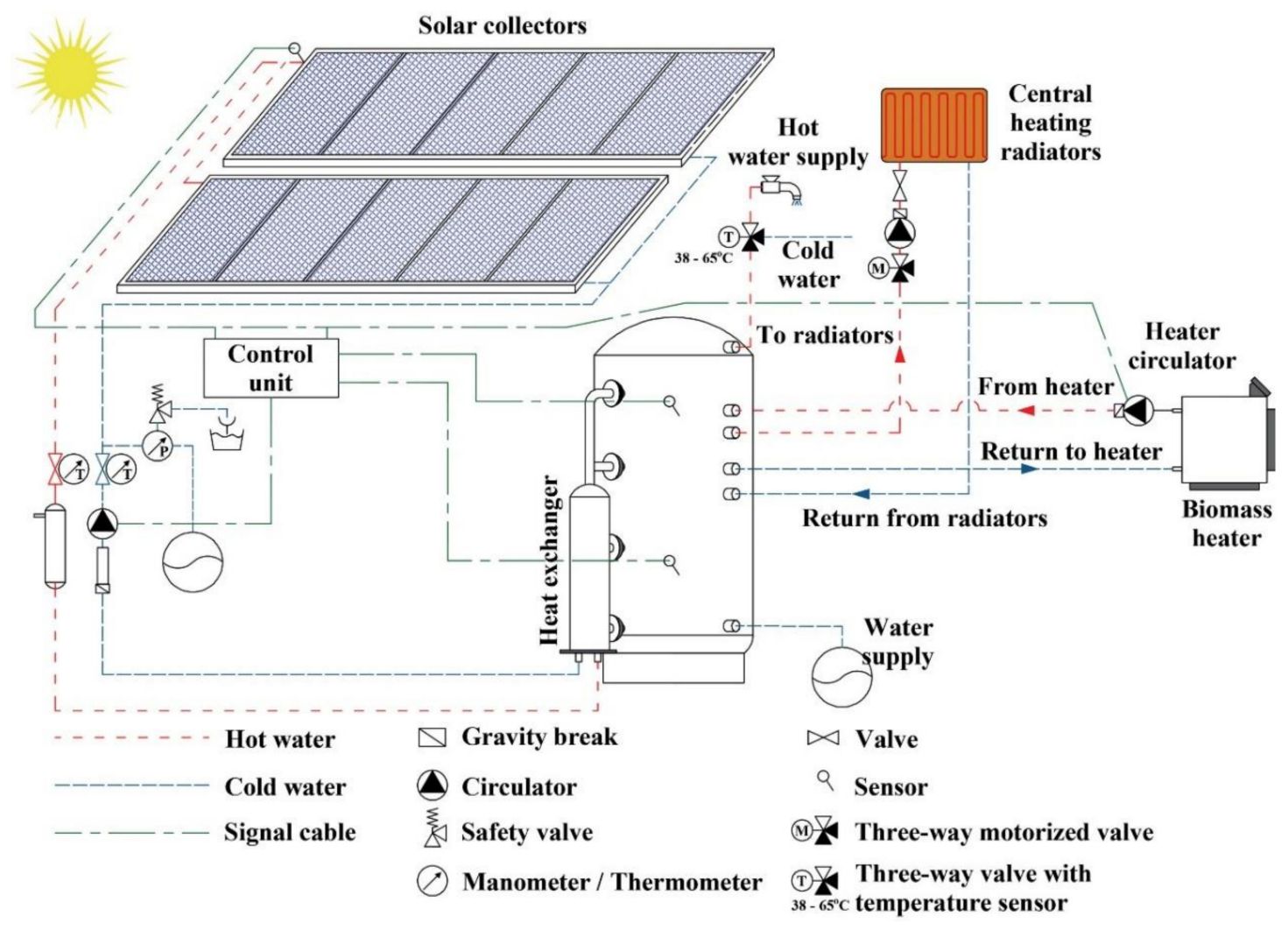

Figure 7. General layout of a solar-combi system.

Additionally, a robust local industry on the design, manufacturing and production of solar collectors has already been developed in Greece. This important industrial activity was triggered by the massive installations of solar collectors since the 1980s, particularly for hot water production in residences and hotels. Greece today holds the third position in Europe, after Cyprus and Austria, in terms of solar collectors' installation area per capita [54].

A similar economic perspective can arise from the exploitation of the locally produced biomass from olive trees pruning. Every year it is estimated that 20,000,000 out of the total 33,000,000 existing olive trees in Crete are pruned. Each olive tree gives $20 \mathrm{~kg}$ of pruning every year and each kilo of pruning gives $0.30 \mathrm{~kg}$ of pellets. It is, as such, roughly calculated that 120,000 tons of biomass pellets can be produced in the island on annual basis. Accounting, roughly, 2 tons of biomass for $1 \mathrm{~m}^{3}$ of diesel oil, it is estimated that the annual potential biomass pellets production in Crete, solely from the olive trees pruning, can substitute $86 \%$ of the $70,000 \mathrm{~m}^{3}$ diesel oil currently consumed annually on the island for indoor space heating. This potential can boost the development of a new, emerging local industry sector, contributing to the enforcement of the local economy.

Furthermore, the installation of a solar-combi system in the largest national stadium in the island, with thousands of daily users and visitors, particularly of young ages, can act as a pilot project, stimulating the local community towards the transition to RES. Finally, the proposed system is the only one that can guarantee $100 \%$ thermal needs coverage with RES (solar radiation and biomass), totally substituting the currently imported oil and the electricity consumption.

\section{Application in the Pancretan Stadium}

\subsection{Climate Conditions-RES Potential}

The annual fluctuation of the Global Horizontal Irradiance $(G H I)$ is presented in Figure 8, measured by a meteorological station at Hellenic Mediterranean University, $2.7 \mathrm{~km}$ away from the stadium's 
location. According to Figure 8, GHI exceeds $1000 \mathrm{~W} / \mathrm{m}^{2}$ during summer, while in winter it ranges between $200 \mathrm{~W} / \mathrm{m}^{2}$ and $400 \mathrm{~W} / \mathrm{m}^{2}$. The yearly global irradiation is calculated at $1780 \mathrm{kWh} / \mathrm{m}^{2}$.

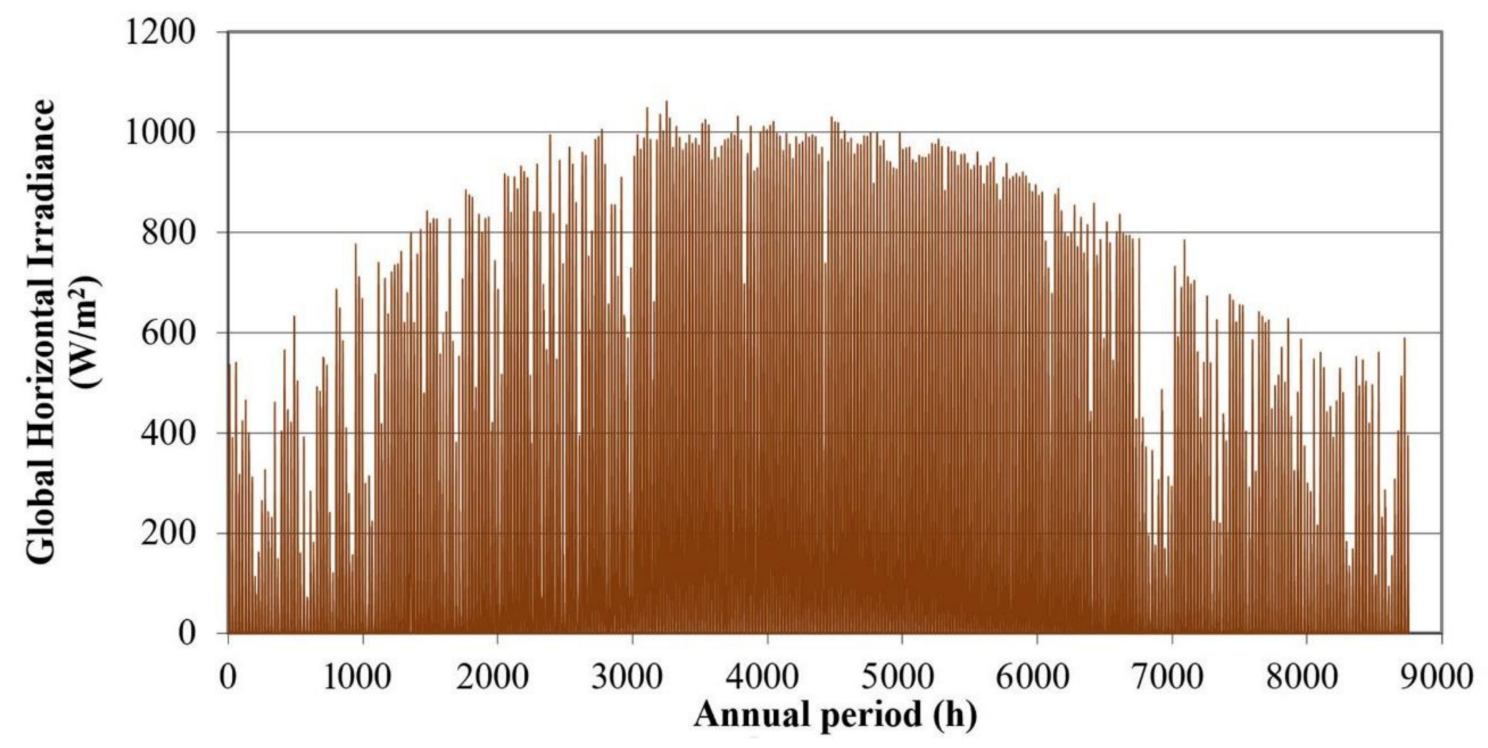

Figure 8. Annual fluctuation of the available Global Horizontal Irradiance at the town of Heraklion.

The annual fluctuation of the ambient temperature is presented in Figure 9, also measured by the above-mentioned station. Finally, in Figure 10, the wind velocity annual time series is presented, measured by a 40-m-high mast installed at the Wind Energy Lab of Hellenic Mediterranean University. The wind velocity is involved in this work for the heat losses calculation from the solar collectors to the environment.

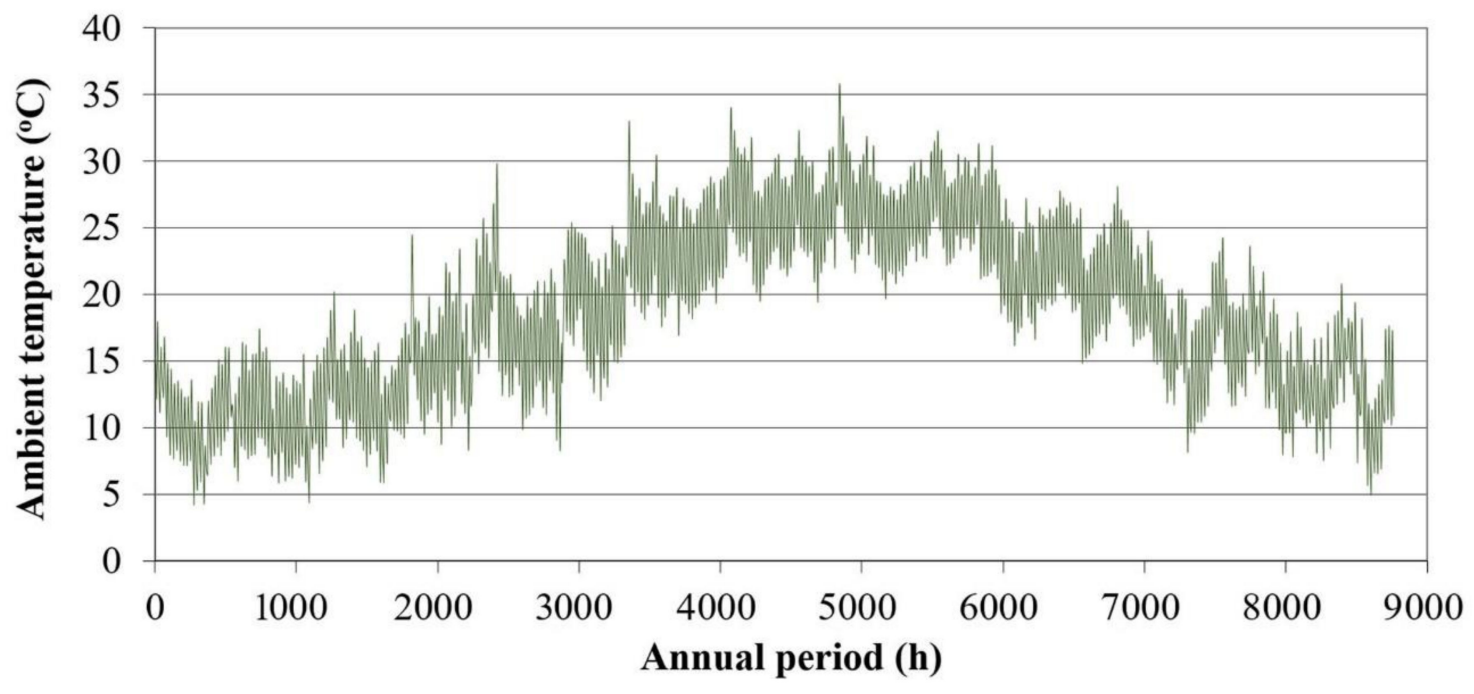

Figure 9. Annual ambient temperature fluctuation at the town of Heraklion. 


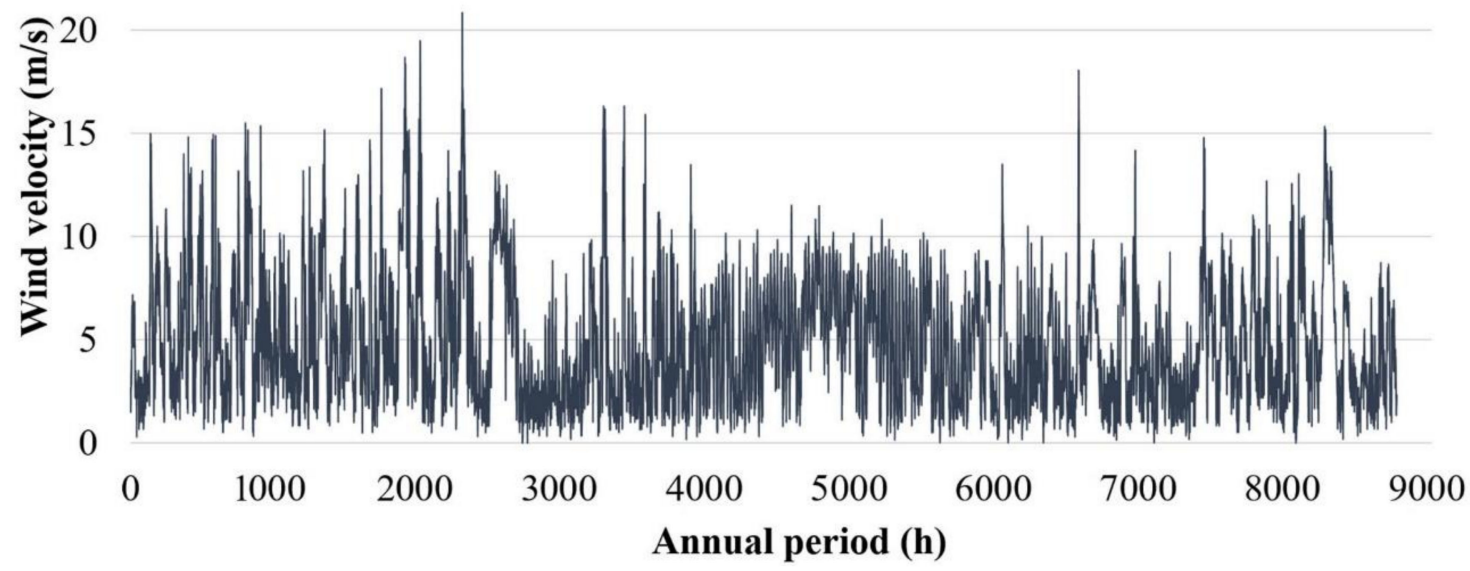

Figure 10. Annual wind velocity fluctuation $2.7 \mathrm{~km}$ away from the location of the stadium.

\subsection{Existing Infrastructure—Siting Parameters}

Currently, hot water is provided for the final users from four thermal tanks, all of them connected to the existing diesel oil burner. Two thermal storage tanks are also connected to the swimming pools, so that thermal power can be also provided for the swimming pools heating alternatively by the storage tanks, instead of the heat pumps. All existing thermal tanks should be replaced by four new ones with the same capacity $(5000 \mathrm{~L})$ for ageing reasons. The introduced solar collectors will be organized in four independent parts, with each one of them connected to a specific thermal storage tank. In this way, four, independent hydraulic networks will be developed, formulating four independent solar-combi systems, all of them supported by a common biomass heater, connected concurrently to all thermal storage tanks. The siting of the four thermal storage tanks and the location selected for the solar collectors' field are presented in Figure 11. The solar collectors' location is sensibly selected at the south-west side of the stadium, to avoid any shading impacts from the stadium.

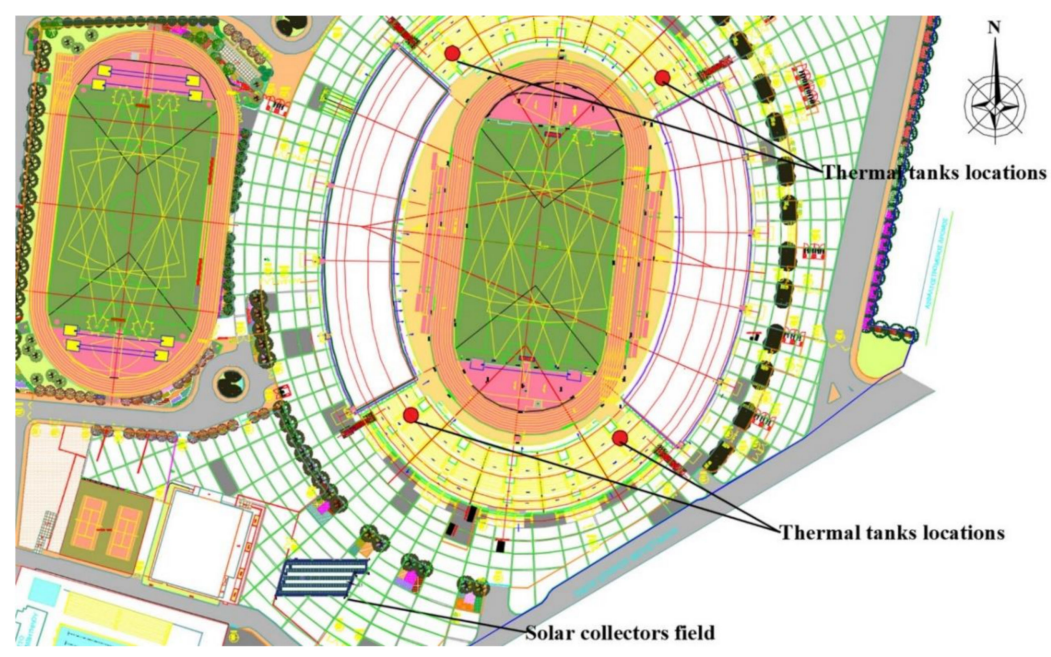

Figure 11. The locations of the solar collectors' installation field and the four thermal storage tanks.

The solar collectors' installation angle was selected aiming to maximize the captured solar radiation both on annual basis and, particularly, during winter period, when the heating needs are increased. For the geographical latitude of the Pancretan Stadium's location $\left(35^{\circ}\right)$, iterative calculations were accomplished of the global incident irradiation on the solar collectors' surface with alternative 
installation angles during winter and during the whole annual period. Given the results presented in Table 5, the finally selected installation angle was $45^{\circ}$.

Table 5. Variation of the incident solar irradiation on the solar collectors' surface, versus their installation angle.

\begin{tabular}{cccccccc}
\hline \multirow{2}{*}{ Solar Radiation } & \multicolumn{7}{c}{ Installation Angle } \\
\cline { 2 - 7 } & $\mathbf{2 0}^{\circ}$ & $\mathbf{3 0 ^ { \circ }}$ & $\mathbf{3 5 ^ { \circ }}$ & $\mathbf{4 0}^{\circ}$ & $\mathbf{4 5}^{\circ}$ & $\mathbf{5 0}^{\circ}$ & $\mathbf{6 0}^{\circ}$ \\
\hline \multicolumn{7}{c}{ Annual incident } & inlar irradiation $\left(\mathrm{kWh} / \mathrm{m}^{2}\right)$ \\
Direct & 1408 & 1453 & 1459 & 1454 & 1438 & 1411 & 1325 \\
Diffused & 630 & 607 & 592 & 574 & 555 & 534 & 488 \\
Reflected & 19 & 43 & 58 & 75 & 94 & 115 & 161 \\
Total & 2057 & 2103 & 2109 & 2103 & 2087 & 2060 & 1974 \\
Incident solar irradiation during & winter- from $15 / 10$ to $15 / 3$ & $\left(\mathrm{kWh} / \mathrm{m}^{2}\right)$ & \\
Direct & 492 & 545 & 565 & 581 & 592 & 599 & 599 \\
Diffused & 168 & 161 & 157 & 153 & 148 & 142 & 130 \\
Reflected & 5 & 12 & 16 & 21 & 26 & 32 & 45 \\
Total & 665 & 718 & 738 & 755 & 766 & 775 & 774 \\
\hline
\end{tabular}

With this angle, both the annual and the winter total incident solar irradiation are very close to their maximum values. The annual fluctuation of the incident solar radiation on the solar collectors' surface for the selected installation angle is presented in Figure 12.

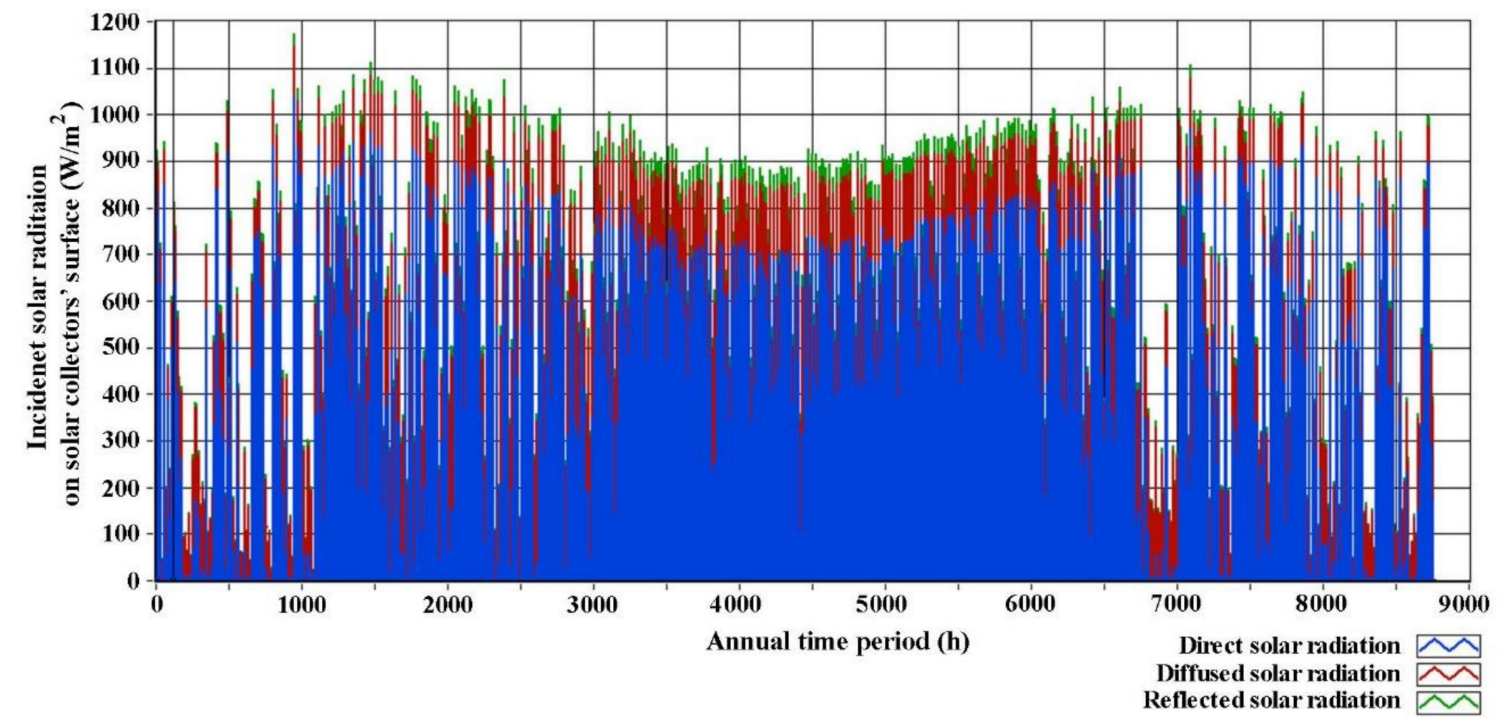

Figure 12. The annual fluctuation of the incident solar radiation on the solar collectors' surface for the selected installation angle of $45^{\circ}$.

The solar collectors will be installed in lines with a south orientation, with a distance of $2.0 \mathrm{~m}$ between them, imposed by the available space. Given this distance, the installation angle and the solar collectors' physical dimensions, a partial shading from the southern to the northern collectors' lines will occur for solar heights up to $36^{\circ}$, as documented in Figure 13a.

The adopted collectors' configuration is shown in Figure 13b: the core unit is formulated by four solar collectors connected in series. A number of these core units will be connected in parallel, formulating, in this way, the solar collectors' field for each of the four independent solar-combi systems. With the adopted connectivity, the essential Tichelmann principle is approached, leading to flow losses reduction and uniform temperature and mass flow rates in the hydraulic network [55]. The number of 
the core units of each independent system will be calculated within the dimensioning process of the solar plant.
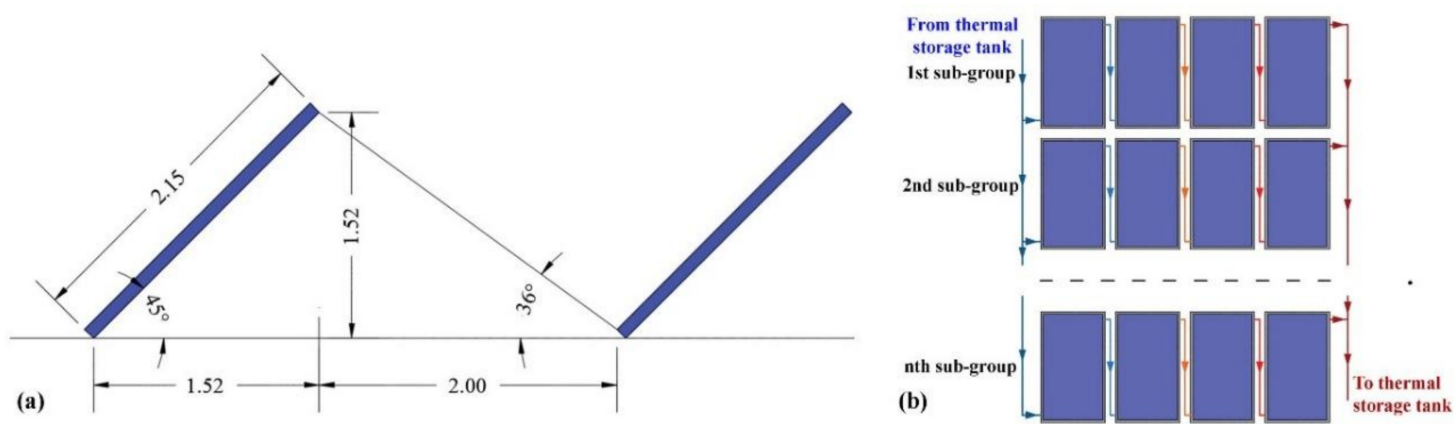

Figure 13. Essential installation and siting features of the solar collectors' field.

\subsection{Mathematical Background-Calculation Process-Dimensioning Methodology}

The mathematical background and the calculation process are presented in brief in this section. Firstly, the required calculation data are introduced, which are:

- The solar collector's effective area: $A_{c}=2.3 \mathrm{~m}^{2}$.

- The total incident solar radiation $G_{t}$ in $\mathrm{W} / \mathrm{m}^{2}$ on the collector's surface (sum of the direct, diffused and reflected solar radiation), presented in Figure 12.

- $\quad$ The ambient temperature $T_{a}$, presented in Figure 9.

- The specific heat capacity of the working fluid $c_{p}$ in $\mathrm{kJ} /(\mathrm{kg} \cdot \mathrm{K})$, practically assumed equal to that of pure water $(4.184 \mathrm{~kJ} / \mathrm{kg} \cdot \mathrm{K})$, in case of water-glycol solution.

- Constructive features and properties of the solar collector:

- $\quad$ the number of the collector's top covers: $N=1$;

- $\quad$ the collector's insulation thickness $t_{e}$ and $t_{b}$ in the side edges and in the bottom respectively: $t_{e}=t_{b}=7 \mathrm{~mm}$;

- the distance $W$ between two consecutive pipelines in the collector (see Figure 14): $W=115 \mathrm{~mm}$;

- the collector's pipeline outer and inner diameter: $D=11 \mathrm{~mm}$ and $D_{i}=10 \mathrm{~mm}$ respectively;

- $\quad$ the thermal conductivity factors of the collector's insulation $k_{e}$ and $k_{b}$ for the side edges and the bottom respectively: $k_{e}=k_{b}=0.0245 \mathrm{~W} /(\mathrm{m} \cdot \mathrm{K})$;

- $\quad$ the emissivity $\varepsilon_{g}$ of the collector's transparent cover: $\varepsilon_{g}=0.88$;

- $\quad$ the emissivity $\varepsilon_{p}$ of the collector's absorber plate: $\varepsilon_{p}=0.95$;

- $\quad$ the thermal conductivity factor $k$ of the absorber plate: $k=350 \mathrm{~W} /(\mathrm{m} \cdot \mathrm{K})$;

- $\quad$ the thickness $\delta$ of the absorber plate: $\delta=0.50 \mathrm{~mm}$ (see Figure 14);

- $\quad$ the thermal conductivity factor $k_{b}$ of the bond's material between the collector's pipelines and the absorber plate: $k_{b}=1000 \mathrm{~W} /(\mathrm{m} \cdot \mathrm{K})$ (see Figure 14);

- the bond's thickness $b$ between the collector's pipelines and the absorber plate: $b=0.60 \mathrm{~mm}$;

- the bond's width $\gamma$ between the collector's pipelines and the absorber plate: $\gamma=0.120 \mathrm{~mm}$.

- Data regarding the particular collector's installation, such as:

- $\quad$ the collector's installation angle $\beta$ in degrees: $\beta=45^{\circ}$;

- $\quad$ the thermal convective factor $h_{f i}$ for the heat transfer from the absorber plate to the working fluid in the collectors' pipelines: $h_{f i}=3000 \mathrm{~W} /\left(\mathrm{m}^{2} \cdot \mathrm{K}\right)$;

- the thermal transition factors $h_{e}$ and $h_{b}$ for the heat losses from the collector's side edges and bottom respectively to the ambient: $h_{e}=h_{b}=10 \mathrm{~W} /\left(\mathrm{m}^{2} \cdot \mathrm{K}\right)$; 
- $\quad$ the mass flow rate $m$ of the working fluid in the collector's pipelines: $m=0.02 \mathrm{~kg} / \mathrm{s} \cdot \mathrm{m}^{2}$ of solar collector's surface.

The calculation process is presented below, executed for every calculation time step.

1. Calculation of the thermal power production from one solar collector.

1.1. Absorber's plate average temperature $\mathrm{T}_{\mathrm{pm}}$ :

The absorber's plate average temperature $T_{p m}$ is initially estimated with the relationship:

$$
T_{p m}=T_{f i}+10 \mathrm{C},
$$

where $T_{f i}$ is the fluid's inlet temperature in the solar collector, assumed equal to the ambient temperature, as an initial condition.

1.2. The thermal transmittance factors:

The total thermal transmittance factor $U_{L}$ for the heat losses from the collector to the ambient is given by the following relationship:

$$
U_{L}=U_{t}+U_{b}+U_{e}
$$

The thermal transmittance factors $U_{b}$ and $U_{e}$ for the heat losses from the collector's bottom and side edges respectively to the ambient are given by the relationship:

$$
U_{e, b}=\frac{1}{\frac{t_{e, b}}{k_{e, b}}+\frac{1}{h_{e, b}}},
$$

The thermal transmittance factor $U_{t}$ for the heat losses from the top of the collector to the ambient is given by the relationship [56]:

$$
U_{t}=\frac{1}{\frac{C}{\frac{C}{T_{p m}} \cdot\left(\frac{T_{p m}-T_{a}}{N+f}\right)^{e}}+\frac{1}{h_{t}}}+\frac{\sigma \cdot\left(T_{p m}+T_{a}\right) \cdot\left(T_{p m}^{2}+T_{a}^{2}\right)}{\frac{1}{\varepsilon_{p}+0.00591 \cdot N \cdot h_{t}}+\frac{2 \cdot N+f-1+0.133 \cdot \varepsilon_{p}}{\varepsilon_{g}}-N},
$$

where:

- $\sigma$ is the Stefan-Boltzam constant (see the nomenclature Table);

- the parameter $C$ is calculated with the following empirical relationship, versus the collector's installation angle $\beta$ (in degrees) [56]:

$$
C=520 \cdot\left(1-0.000051 \cdot \beta^{2}\right)
$$

- the parameter $f$ is given by the following empirical relationship, versus the number $N$ of the collector's transparent top covers, the absorber plate emissivity $\varepsilon_{p}$ and the thermal transition factor $h_{t}$ for the heat losses from the collector to the ambient [56]:

$$
f=\left(1+0.089 \cdot h_{t}-0.1166 \cdot h_{t} \cdot \varepsilon_{p}\right) \cdot(1+0.07866 \cdot N),
$$

- the parameter $e$ is given by the following empirical relationship versus the average temperature of the absorber plate $T_{p m}$ (in K) [56]:

$$
e=0.430 \cdot\left(1-\frac{100}{T_{p m}}\right)
$$

1.3. The heat removal factor $F_{R}$ : 
The heat removal factor is calculated with the relationship [56]:

$$
F_{R}=\frac{m \cdot c_{p}}{A_{c} \cdot U_{L}} \cdot\left[1-\exp \left(-\frac{A_{\mathcal{c}} \cdot U_{L} \cdot F^{\prime}}{m \cdot c_{p}}\right)\right]
$$

The parameter $F^{\prime}$ is calculated with the following relationship for flat-plate collectors [56]:

$$
F^{\prime}=\frac{\frac{1}{U_{L}}}{W \cdot\left[\frac{1}{U_{L} \cdot[D+(W-D) \cdot F]}+\frac{1}{C_{b}}+\frac{1}{\pi \cdot D_{i} \cdot h_{f i}}\right]},
$$

The standard fin efficiency $F$ is given by the following relationship versus the collector's dimensions $W$ and $D$ (Figure 14) [56]:

$$
F=\frac{\tanh \left[\frac{m \cdot(W-D)}{2}\right]}{\frac{m \cdot(W-D)}{2}},
$$

where the parameter $m$ is defined versus the absorber's plate thermal conductivity factor $k$ and thickness $\delta$ (Figure 14) by the relationship [56]:

$$
m=\sqrt{\frac{U_{L}}{k \cdot \delta}}
$$

The bond conductance between the collector's pipelines and the absorber plate is calculated with the relationship [56]:

$$
C_{b}=\frac{k_{b} \cdot b}{\gamma}
$$

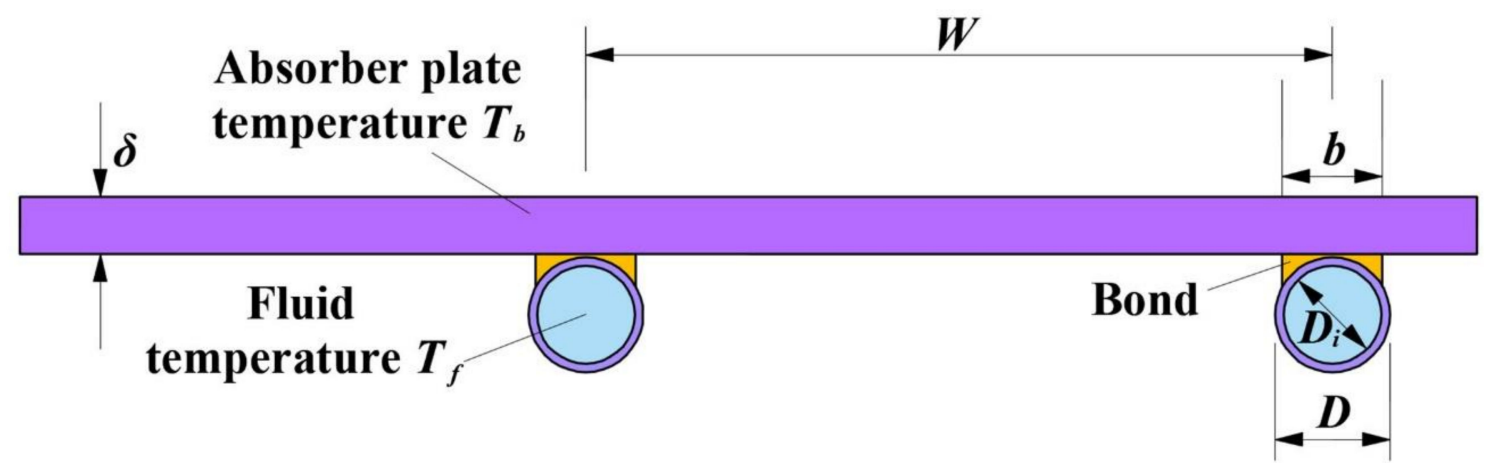

Figure 14. Inner structural layout of a flat-plate solar collector.

1.4. The transmittance-absorbance product $(\tau \cdot \alpha)$ :

The transmittance-absorbance product $(\tau \cdot \alpha)$ should be calculated for every calculation time step versus the solar radiation incident angle. The product $(\tau \cdot \alpha)$ is given by the collector's manufacturer in the form of a diagram or table sheet versus the solar radiation incident angle, as indicatively presented in Figure 15 [56]. The transmittance-absorbance product $(\tau \alpha)_{n}$ for perpendicular incidence of the solar radiation on the solar collector must be also known.

For higher accuracy, the effective transmittance-absorbance $(\tau \alpha)_{e}$ product can be eventually used. For solar collectors with glass cover (high absorbance), it is calculated, with the following relationship [56]:

$$
(\tau \cdot \alpha)_{e} \cong 1.02 \cdot(\tau \cdot \alpha)
$$




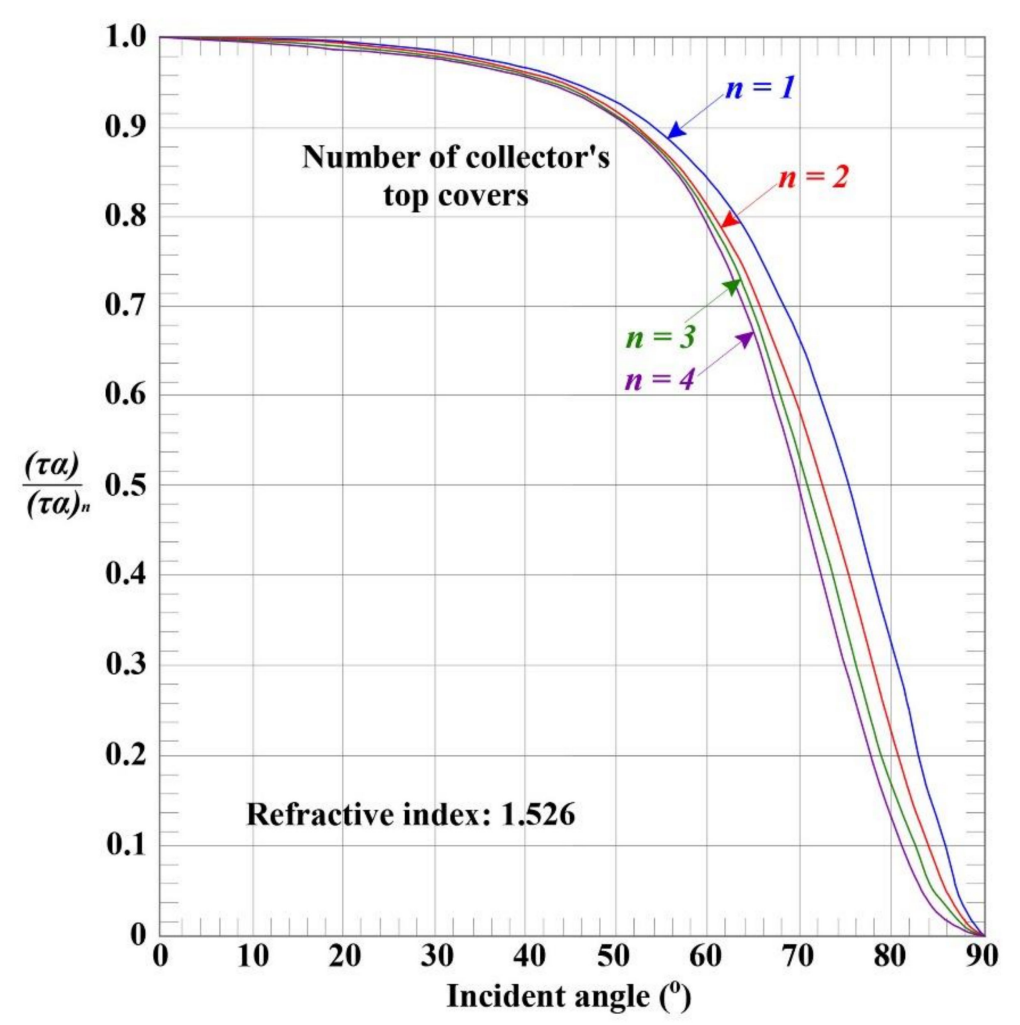

Figure 15. Fluctuation of the transmittance-absorbance product of solar collectors with a different number of top covers, versus the solar radiation incident angle.

1.5. Calculation of the thermal power production from the solar collector:

The thermal power production from one solar collector is eventually given by the following relationship [56]:

$$
Q=A_{c} \cdot F_{R} \cdot\left[G_{t} \cdot(\tau \cdot \alpha)_{e}-U_{L} \cdot\left(T_{f i}-T_{a}\right)\right]
$$

1.6. Confirmation of the initial assumption:

The initial assumption for the absorber's plate average temperature $T_{p m}$ must now be verified with the following relationship [56]:

$$
T_{p m}=T_{f i}+\frac{Q / A_{c}}{F_{R} \cdot U_{L}} \cdot\left(1-F_{R}\right),
$$

If there is significant divergence between the initial assumption (step 1) for the temperature $T_{p m}$ and the final calculated value in this current step; then, steps $2-5$ are executed again by introducing the new calculated temperature $T_{p m}$.

The above presented procedure for the thermal power production calculation from one solar collector is graphically presented in Figure 16. 


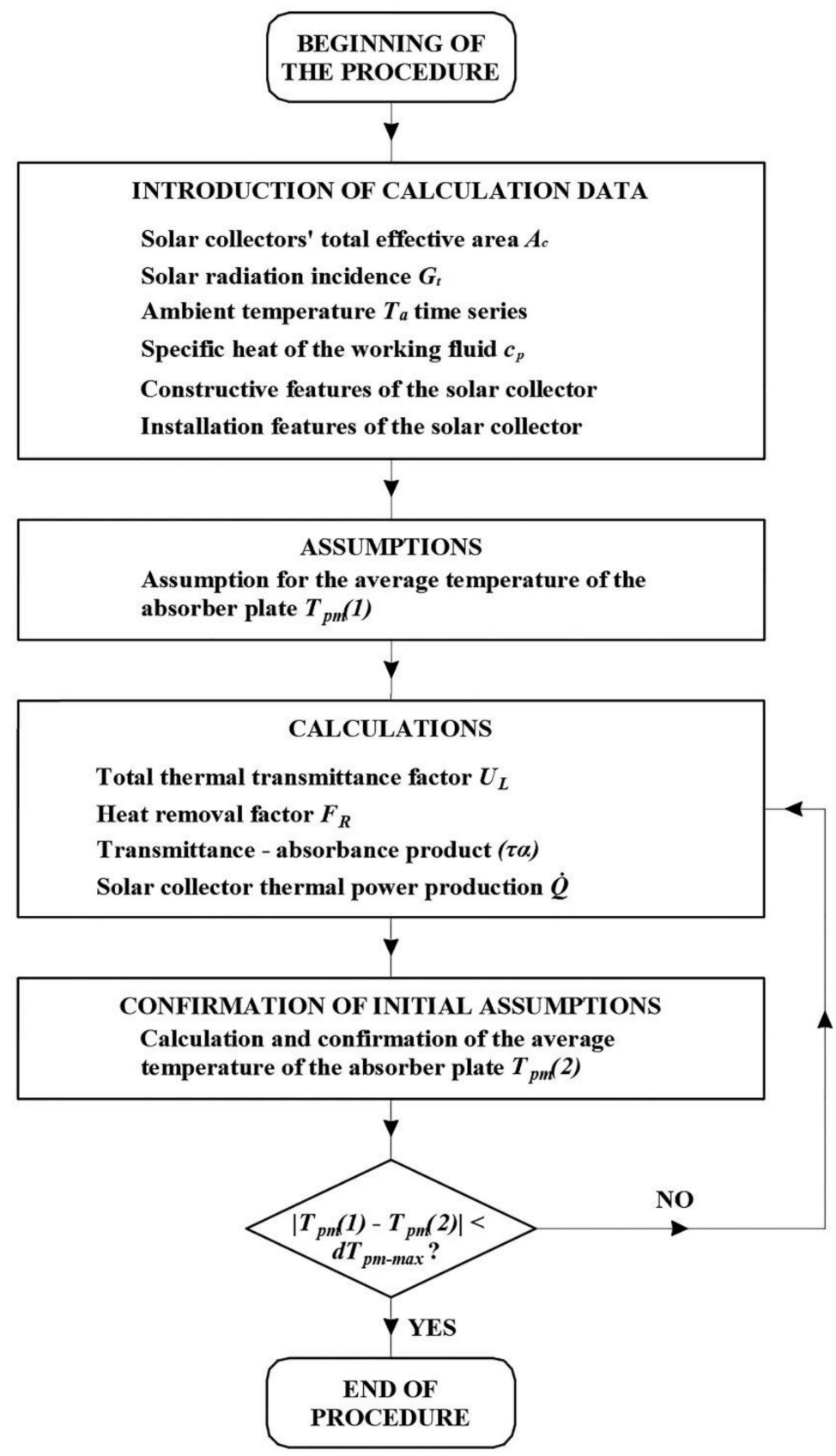

Figure 16. Flow diagram of the calculation procedure for the thermal power production from a flat-plate solar collector.

2. Thermal power production from solar collectors connected in series and in parallel:

The above presented procedure is applied iteratively for all solar collectors of the same, in series connected sub-group. The working medium inlet temperature for the next solar collector equals to the outlet temperature from the previous solar collector and so on. This is simply calculated by the relationship:

$$
Q=m \cdot c_{p} \cdot\left(T_{\text {out }}-T_{\text {in }}\right) \Leftrightarrow T_{\text {out }}=\frac{Q}{m \cdot c_{p}}+T_{\text {in }},
$$

By adding the thermal power production of all solar collectors connected in series, the thermal power production from each sub-group is calculated. The last step is the aggregation of the thermal power production from the in parallel connected sub-groups for the calculation of the total power production $Q_{\text {tot }}$ from each solar-combi system. 
3. Thermal power storage in the thermal storage tank:

Following the process described in the previous step, the final outlet temperature $T_{\text {out }}$ is calculated from each in-series connected solar collectors group. With this temperature, the produced thermal power will be transferred to the thermal storage tanks. If this temperature is higher than the water temperature $T_{s}(i-1)$ in the thermal storage tanks from the previous calculation step, then the thermal power produced $Q_{t o t}$ by each solar-combi system is stored. Otherwise, the produced thermal power by the solar collectors cannot be exploited, practically there is no circulation in the solar collectors' primary loop. As it will be shown in the results section, due to the considerable final thermal energy needs during the whole annual period, no issues due to the solar collectors overheating are expected.

4. Thermal power production from the biomass heater:

Any potential thermal power demand $Q_{d}$ should be provided by the thermal power stored in the thermal tanks. In case the thermal power $Q_{\text {tot }}$ provided by the solar collectors is not adequate to cover the current thermal power demand $Q_{d}$, the biomass heater is put on duty to undertake the remaining thermal demand: $Q_{b}=Q_{d}-Q_{t o t}$. This equation is applied on a daily basis.

5. New water temperature in the storage tank:

The procedure is integrated with the calculation of the water temperature $T_{s}(i)$ in the thermal tank at the end of each calculation time step $i$, with the relationship:

$$
T_{s}(i)=\frac{\left\{Q_{t o t}+Q_{b}-Q_{d}-U_{s} \cdot A_{s} \cdot\left[T_{s}(i-1)-T_{a}\right]\right\} \cdot t}{m \cdot c_{p}}+T_{s}(i-1),
$$

where $U_{s}, A_{s}$ the thermal transmittance factor and the heat transfer area of the thermal storage tank, $\mathrm{m}$ the total water mass in the tank and $\mathrm{t}$ the duration of the calculation time step (see nomenclature Table). The last term in the numerator of this last relationship stands for the heat losses from the thermal storage tank to the ambient.

From the above analysis, it is conceivable that the calculation process is executed separately for each of the four independent solar-combi systems.

The above methodology is executed iteratively for different scenarios regarding the size of the solar collectors' field. The dimensioning objective is the highest possible coverage of the annual thermal energy demands from the solar collectors (in any case higher than 50\%) with the concurrent economic feasibility of the investment.

\subsection{Swimming Pools Heating Load with the Introduction of Passive Measures}

A floating insulating cover is proposed as a passive measure, aiming at a reduction in the swimming pools' heating loads. It will be placed on the swimming pools' free surface whenever they are not in use.

The swimming pools heating loads are calculated again, by applying the same methodology presented in Section 2.3, yet this time with the use of the floating insulating cover. Practically the only change is that the U-factor for the heat transfer from the insulating cover to the indoor space should be calculated with the following relationship:

$$
U_{c}=\frac{1}{\frac{1}{h_{w}}+\frac{d_{c}}{k_{c}}+\frac{1}{h_{f c}}}
$$

where $h_{w}$ is the convective heat transfer factor of still water, $d_{c}$ is the floating insulating cover thickness and $k_{c}$ is the floating insulating cover conductivity coefficient, given by the manufacturer (see Table 2 for the adopted values). The material of the insulating cover is polyethylene. Obviously, during the daily operation hours of the swimming pools, the insulating cover will be removed, and the calculation process presented in Section 2.3 will still be applied. 
The factor $h_{f c}=h_{r c}+h_{c}$ is the total heat transfer factor from the insulating cover to the indoor space, calculated as the sum of the convective heat transfer factor $h_{c}$ for indoor space air flows above horizontal surfaces and the radiation heat transfer factor $h_{r c}$ of the insulating material, given by the relationship (4), by replacing the emissivity of water with the emissivity of the insulating material $\varepsilon_{c}$ (see Table 2).

The annual fluctuation in the swimming pools heating loads with the introduction of the insulating cover is presented in Figure 17. The new, annual final thermal energy required for the swimming pools heating is calculated at $54,620 \mathrm{kWh}$; namely, a $51.3 \%$ reduction is achieved compared to the existing operation $(112,216 \mathrm{kWh}$, see Table 3$)$, solely with the use of this passive measure. With the reduced swimming pools' annual heating loads, the total annual thermal energy needs for the consumptions under consideration (swimming pools' heating and hot water consumption) is calculated at 315,635 kWh.

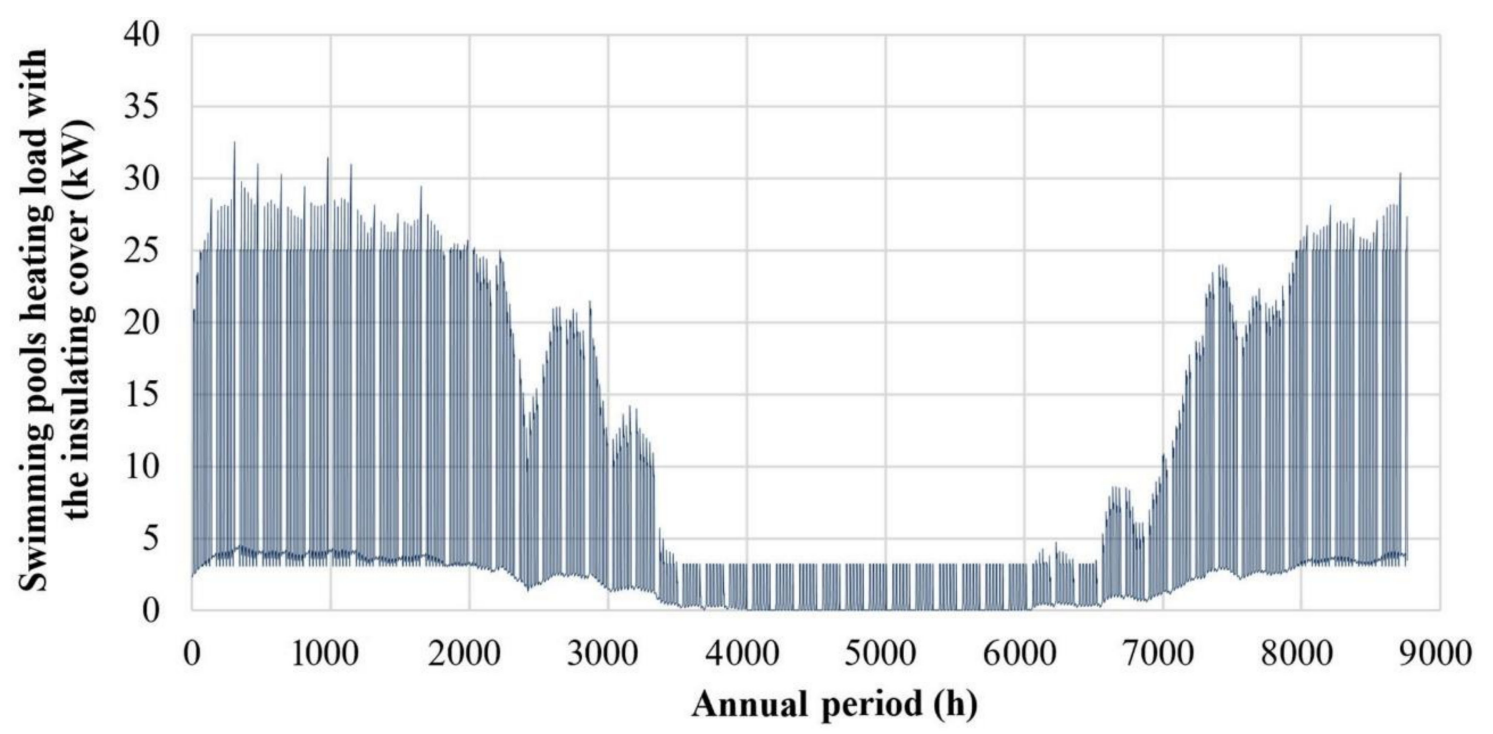

Figure 17. Annual thermal power required for the swimming pools' heating with the introduction of the insulating cover.

\section{Results}

Several iterative executions of the computational simulation process were accomplished, varying the solar collectors' number and keeping unchanged all the required hydraulic equipment (pipelines, circulators, expansions vessels), the biomass heater and the four thermal storage tanks.

Given the solar collectors' adopted layout, presented in Section 4.2, each new iterative calculation was executed by introducing four additional in-series connected solar collectors for each of the four independent solar-combi systems, namely in total 16 collectors are additionally introduced with each new iterative calculation. The iterations start with 24 groups of four in-series connected solar collectors (six groups for each of the four independent solar-combi systems), namely 96 solar collectors in total. The as such formulated alternatively investigating scenarios are summarized in Table 7, together with the results of the iterative calculations.

The dimensioning of the proposed system is optimized versus the payback period, calculated for the total set-up cost of the proposed system and on the basis of the avoided operation cost, achieved through the elimination of the diesel oil and the electricity consumption for hot water production and swimming pools heating in the stadium (see Table 4). It must be clarified that all the tasks required for the operation and the maintenance of the solar-combi systems (practically the regular cleaning and maintenance of the biomass heater and the solar collectors' top cover cleaning once or twice annually) will be undertaken by the existing technical staff in the Pancretan Stadium. This means that 
no additional staff will be employed. For this reason, no labor costs were taken into account for the payback period calculation.

In Table 6, the total set-up cost of the proposed solar-combi system is presented, versus the alternative investigated dimensioning scenarios. All these costs are based on real quotations received by relevant manufacturers-providers and on the detailed application study. As seen in Table 6, the biomass heater's nominal power is imposed by the annual peak thermal power demand $(133 \mathrm{~kW}$, $115,000 \mathrm{kcal} / \mathrm{h})$.

Table 6. Set-up cost analysis of the proposed solar-combi system, versus the investigated dimensioning scenarios.

\begin{tabular}{|c|c|c|c|c|c|}
\hline Scenario Number & 1 & 2 & 3 & 4 & 5 \\
\hline System's Component & \multicolumn{5}{|c|}{ Procurement and Installation Cost (EUR) } \\
\hline Biomas heater $150,000 \mathrm{kcal} / \mathrm{h}$ & & & 25,000 & & \\
\hline Cyclonic filter & & & 10,000 & & \\
\hline Electrical panel & & & 3000 & & \\
\hline Biomass tank $8 \mathrm{~m}^{3}$ & & & 5000 & & \\
\hline Four thermal tanks $5000 \mathrm{~L}$ each & & & 32,000 & & \\
\hline Copper pipelines with insulations & & & 60,000 & & \\
\hline Expansion vessels & & & 2000 & & \\
\hline Circulators & & & 5000 & & \\
\hline Swimming pools insulation cover & & & 10,000 & & \\
\hline Solar collectors & 38,400 & 44,800 & 51,200 & 57,600 & 64,000 \\
\hline Total set-up cost & 190,400 & 196,800 & 203,200 & 209,600 & 216,000 \\
\hline
\end{tabular}

The results of the iterative calculations are presented in Table 7, with the following assumptions:

- Selective coating, flat plate solar collector procurement price: $400 \mathrm{EUR} /$ collector;

- Biomass pellets heat capacity: $5.2 \mathrm{kWh} / \mathrm{kg}$;

- Biomass heater efficiency: $85 \%$;

- Heating distribution system efficiency: $95 \%$;

- Biomass pellets price (in Crete): $350 \mathrm{EUR} / \mathrm{tons}$.

Table 7. Results of the iterative dimensioning procedure.

\begin{tabular}{|c|c|c|c|c|c|}
\hline Investigating Scenario & 1 & 2 & 3 & 4 & 5 \\
\hline Solar collectors number & 96 & 112 & 128 & 144 & 160 \\
\hline Solar collectors' initial thermal energy production (kWh) & 146,677 & 169,816 & 192,948 & 216,081 & 239,214 \\
\hline Solar collectors' thermal energy storage (kWh) & 144,183 & 161,039 & 174,799 & 186,648 & 198,495 \\
\hline Solar collectors' thermal energy surplus (kWh) & 2494 & 8777 & 18,149 & 29,433 & 40,719 \\
\hline Biomass thermal energy production (kWh) & 171,452 & 154,596 & 140,836 & 128,987 & 117,140 \\
\hline Solar collectors' annual penetration percentage (\%) & 45.68 & 51.02 & 55.38 & 59.13 & 62.89 \\
\hline $\begin{array}{c}\text { Solar collectors' annual thermal energy surplus } \\
\text { percentage }(\%)\end{array}$ & 0.79 & 2.78 & 5.75 & 9.33 & 1200 \\
\hline Biomass pellets annual consumption (tons) & 40.83 & 36.82 & 33.54 & 30.72 & 27.90 \\
\hline Biomass pellets annual procurement cost (EUR) & 14,291 & 12,886 & 11,739 & 10,751 & 9764 \\
\hline Annual, net monetary saving (EUR) & 35,342 & 36,747 & 37,894 & 38,882 & 39,870 \\
\hline Investment's payback period (years) & 5.39 & 5.36 & 5.36 & 5.39 & 5.42 \\
\hline Thermal energy specific production cost (EUR/kWh) & 0.0650 & 0.0627 & 0.0610 & 0.0597 & 0.0584 \\
\hline
\end{tabular}


The thermal energy annual specific production cost, presented at the last row of Table 7 , was calculated with the following relationship:

$$
\text { L.C. }=\frac{\frac{I . C .}{L}+\frac{\sum_{n=1}^{L} \frac{A . O . C .}{(1+i)^{n}}}{L}}{E_{t h}},
$$

where:

L.C.: $\quad$ the annually average, thermal energy production specific cost (in EUR/kWh);

I.C.: $\quad$ the set-up cost of the solar-combi system (in EUR);

A.O.C.: $\quad$ the overall annual operation and maintenance cost (in EUR/year);

$i$ : $\quad$ the discount rate, adopted equal to $3 \%$;

L: $\quad$ the total life period of the solar-combi system, adopted equal to 20 years;

$n$ : $\quad$ the number of the current year of the system's operation;

$E_{t h}$ : the total annual thermal energy production of the solar-combi system, equal to $315,635 \mathrm{kWh}$.

The A.O.C. was calculated as the sum of the annual biomass fuel consumption cost and an average (over the system's life period) maintenance cost of EUR 500, referring to the annual regular maintenance of the biomass heater. It must be underlined that the procurement cost of the electricity consumption in the hydraulic network's circulators and any other auxiliary loads was not included in A.O.C., although, substantially it should have been. However, this choice can be justified with the following arguments:

- The calculation of these electricity consumptions would impose a detailed writing down of all the involved hydraulic network with its components, which on the one hand would require considerable amount of additional work and, on the other, is beyond the scope of the present article, which is the dynamic simulation and the dimensioning of the introduced system.

- The contribution of the annual electricity consumption in the circulators and the auxiliary loads would be, more or less, the same, regardless of the dimensioning of the solar-combi system. So, conclusively, it would not affect the optimization of the dimensioning, as there would be an analogous increase in the total L.C. for all the investigated scenarios.

- Finally, this electricity consumption already exists in the current operation state of the heating production system in the examined sports facility. Hence, since the payback period is calculated on the basis of the avoided diesel oil and electricity consumption cost of the current operation, the payback period is not affected by this particular operation cost component.

By observing the results presented in Table 7, it can be seen that all the investigated dimensioning scenarios exhibit very low payback periods, at the range of 5.5 years. This is due to the high achieved solar collectors' annual penetration, the corresponding low biomass annual consumption and the existing high procurement cost of diesel oil and electricity. Practically, this considerably high existing cost sets the basis for the economic feasibility of the proposed system. Additionally, the economic feasibility of the proposed system is highly favored by the considerable thermal energy needs in the stadium during the whole year, unlike other case studies with intensive thermal energy demand seasonality (e.g., indoor space heating for residential or commercial buildings), investigated in relevant scientific articles.

Another positive consequence of the above favorable conditions is also the considerably low annual thermal energy specific production cost, formulated at the range $0.06 \mathrm{EUR} / \mathrm{kWh}$, increasing the economic competitiveness of the proposed system with regard to other, advanced systems (e.g., photovoltaic thermal hybrid panels).

All the investigated scenarios exhibit very close payback periods. This is because the only varying component between the different investigated dimensioning scenarios is the solar collectors' number, which only makes a low contribution to the system's total set-up cost.

The annual thermal energy surplus increases, as is normally expected, with the solar collectors' number. The absorbance of this surplus would require additional storage capacity. Yet, this would considerably increase the total set-up cost, negatively affecting the investment's payback period. 
The optimum scenario seems to be the installation of 128 solar collectors, namely 32 solar collectors for each independent solar-combi system (eight groups of four in-series connected solar collectors for each system). The executed simulation results particularly for this scenario are presented in Table 8 .

Table 8. New thermal power demand and analysis of thermal power production with the proposed solar-combi system.

\begin{tabular}{|c|c|c|c|c|}
\hline \multicolumn{2}{|c|}{ Heating Load } & Hot Water Production & Swimming Pools Heating & Total \\
\hline \multicolumn{2}{|c|}{ Thermal energy demand (kWh) } & 261,015 & 54,620 & 315,635 \\
\hline Thermal energy & Solar collectors & 169,700 & 5099 & 174,799 \\
\hline production (kWh) & Biomass & 91,315 & 49,521 & 140,836 \\
\hline \multicolumn{2}{|c|}{ Biomass consumption (tons) } & 20.609 & 10.588 & 31.197 \\
\hline \multicolumn{2}{|c|}{ Primary energy consumption (kWh) } & 119,365 & 61,326 & 180,691 \\
\hline
\end{tabular}

From Tables 3 and 8 , it is revealed that the overall influence of both the introduced passive measure and the solar-combi system is a total primary energy annual saving of $75.6 \%$ (from $741,798 \mathrm{kWh}$ to $180,690 \mathrm{kWh}$ ). The diesel oil and electricity consumption are eliminated for the final thermal energy uses under consideration.

For the optimum dimensioning scenario (128 solar collectors), the solar collectors' and the biomass heater annual total thermal power production, and the water temperature fluctuation in the thermal storage tanks, are presented in Figures 18-20, respectively.

As seen in Figure 20, the maximum annual water temperature in the storage tank is slightly higher than $80^{\circ} \mathrm{C}$. No circulation in the solar collectors' primary loop occurs when the temperature in this primary loop is lower than the current temperature in the thermal storage tank. This practically means that when there is no circulation in the primary loop, the working medium's temperature in the primary loop cannot be higher than $80^{\circ} \mathrm{C}$; hence, normally, no overheating issues are expected in the solar collectors' loops. In general, these issues may occur in cases of considerably low-or, even worse, null-thermal loads over extensive time periods (e.g., during summer). However, in this case study, there are considerable heating loads during the whole annual period, due to the hot water needs, as seen in Figure 3.

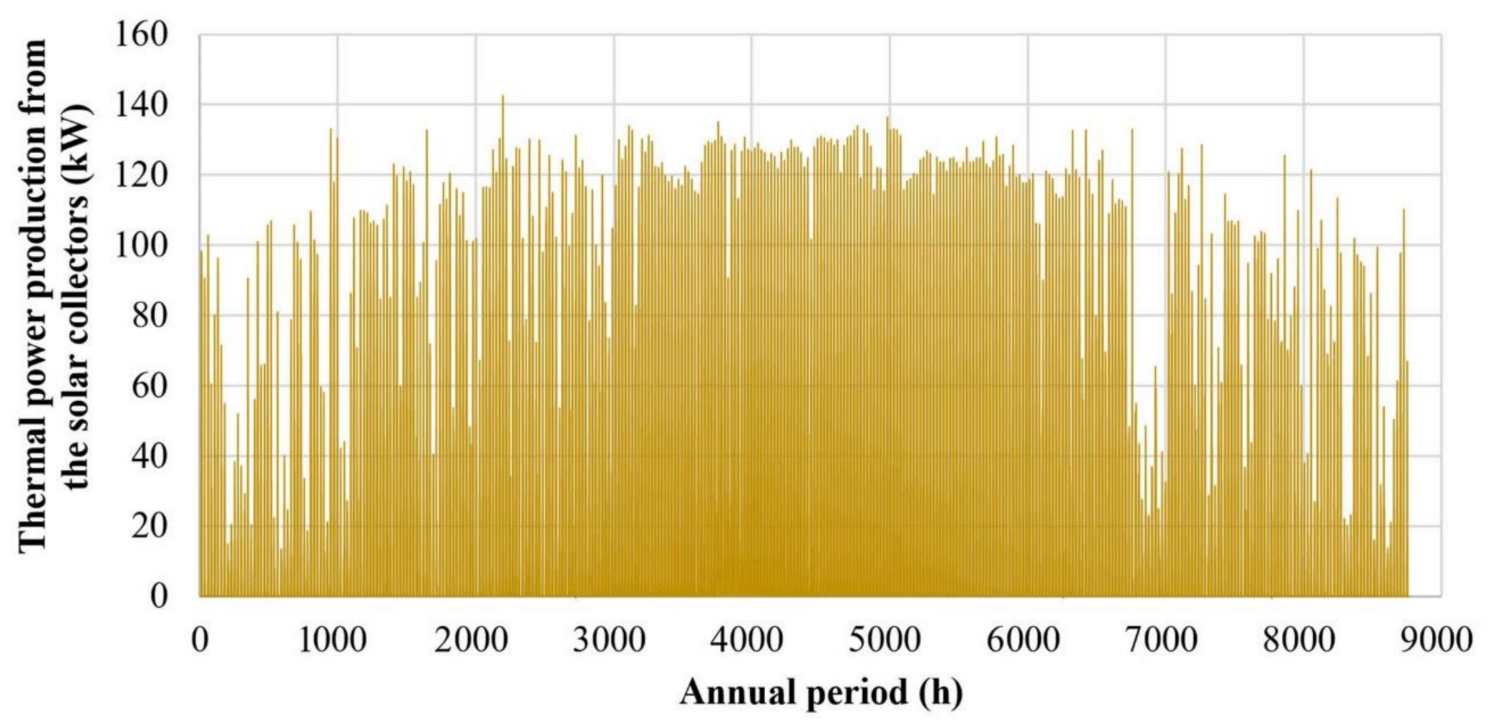

Figure 18. Annual fluctuation of the final thermal power stored in the thermal storage tanks by the solar collectors. 


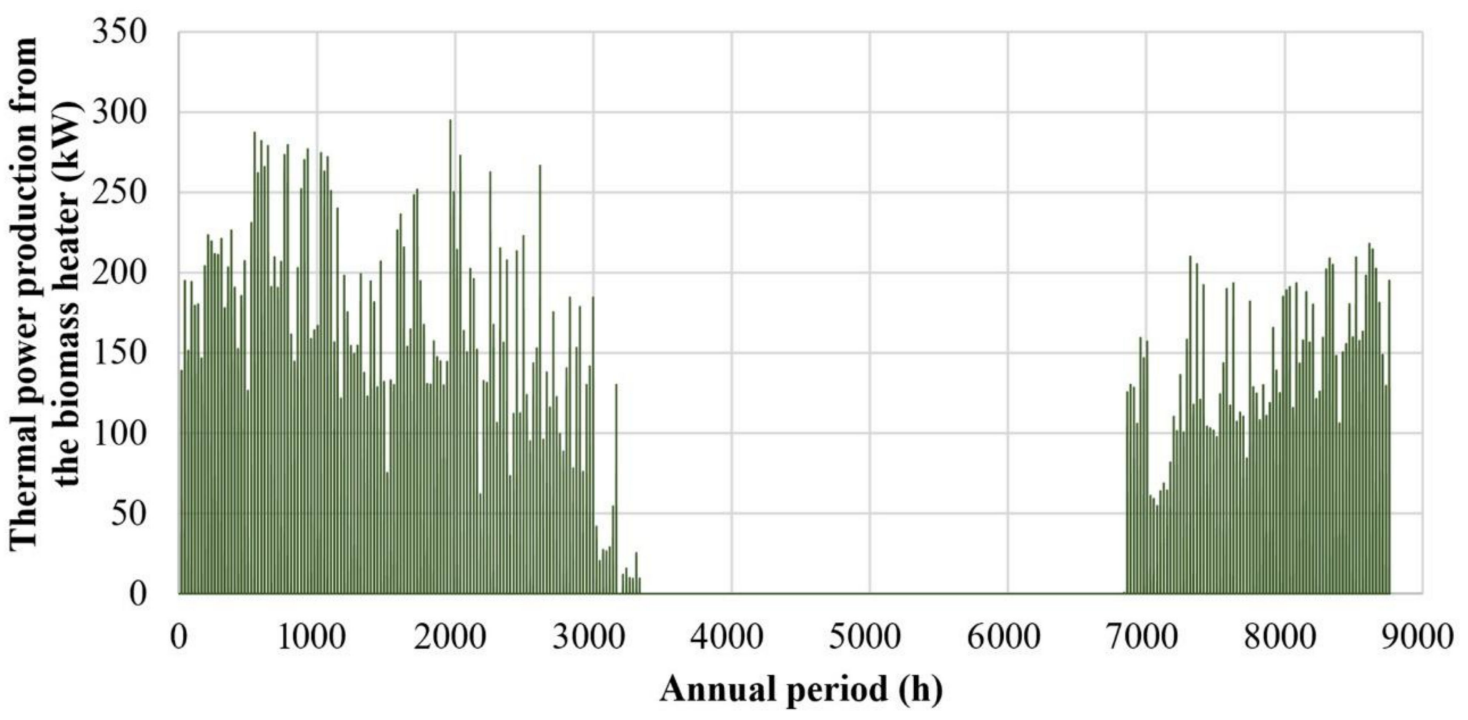

Figure 19. Annual fluctuation of the thermal power production from the biomass heater.

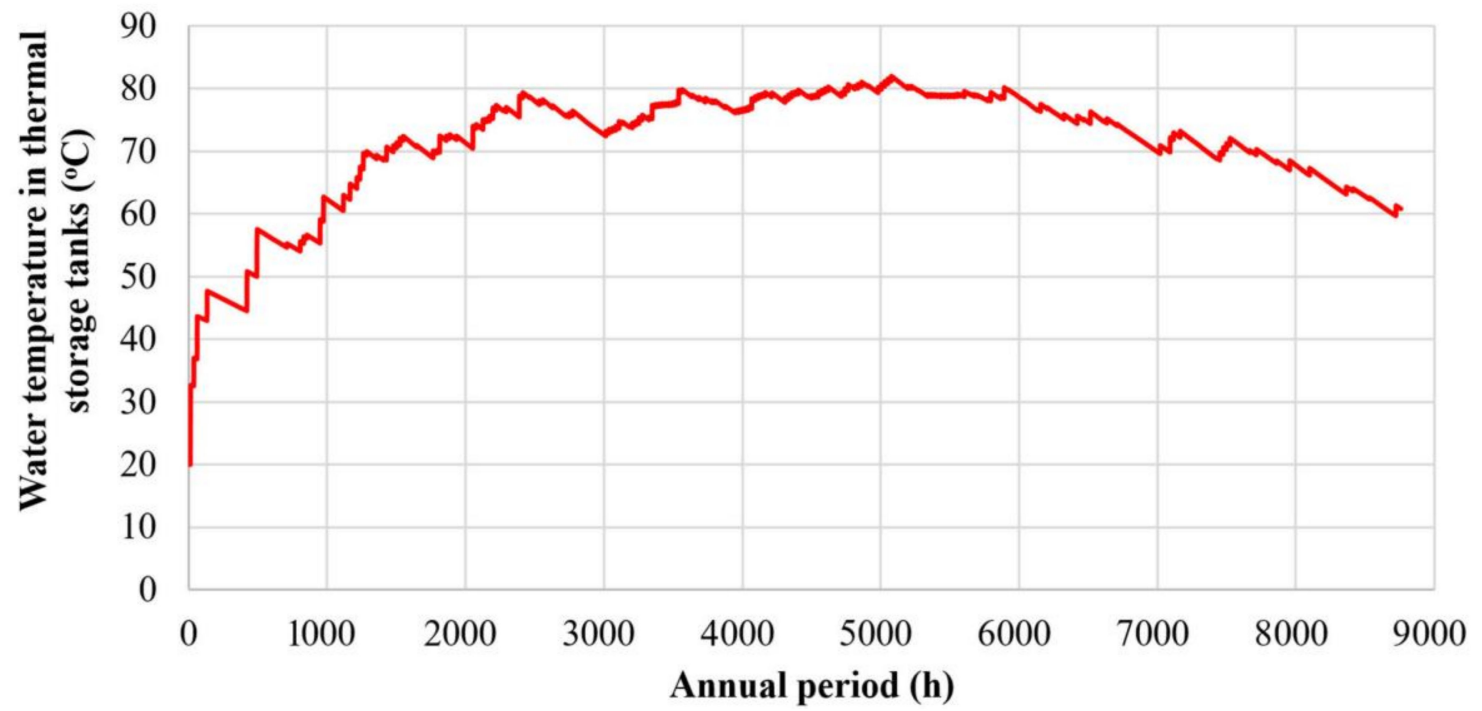

Figure 20. Annual fluctuation of water temperature in the thermal storage tanks.

In Figure 20, it is also seen that the water temperature in the thermal storage tanks remains during the annual period almost constantly higher than $55^{\circ} \mathrm{C}$, apart from the beginning of the year, due to the assumed initial water temperature (equal to $20^{\circ} \mathrm{C}$ ) adequately treating any potential impacts of Legionnaire's disease on the secure system's usage.

In Figure 21, the annual fluctuation of the daily fractions of the solar collectors' and the biomass thermal energy production versus the thermal energy demand is presented. It can be seen that during summer there is considerable thermal energy production surplus from the solar collectors, which is stored in the thermal storage tanks, postponing the operation of the biomass heater again until mid-October. 


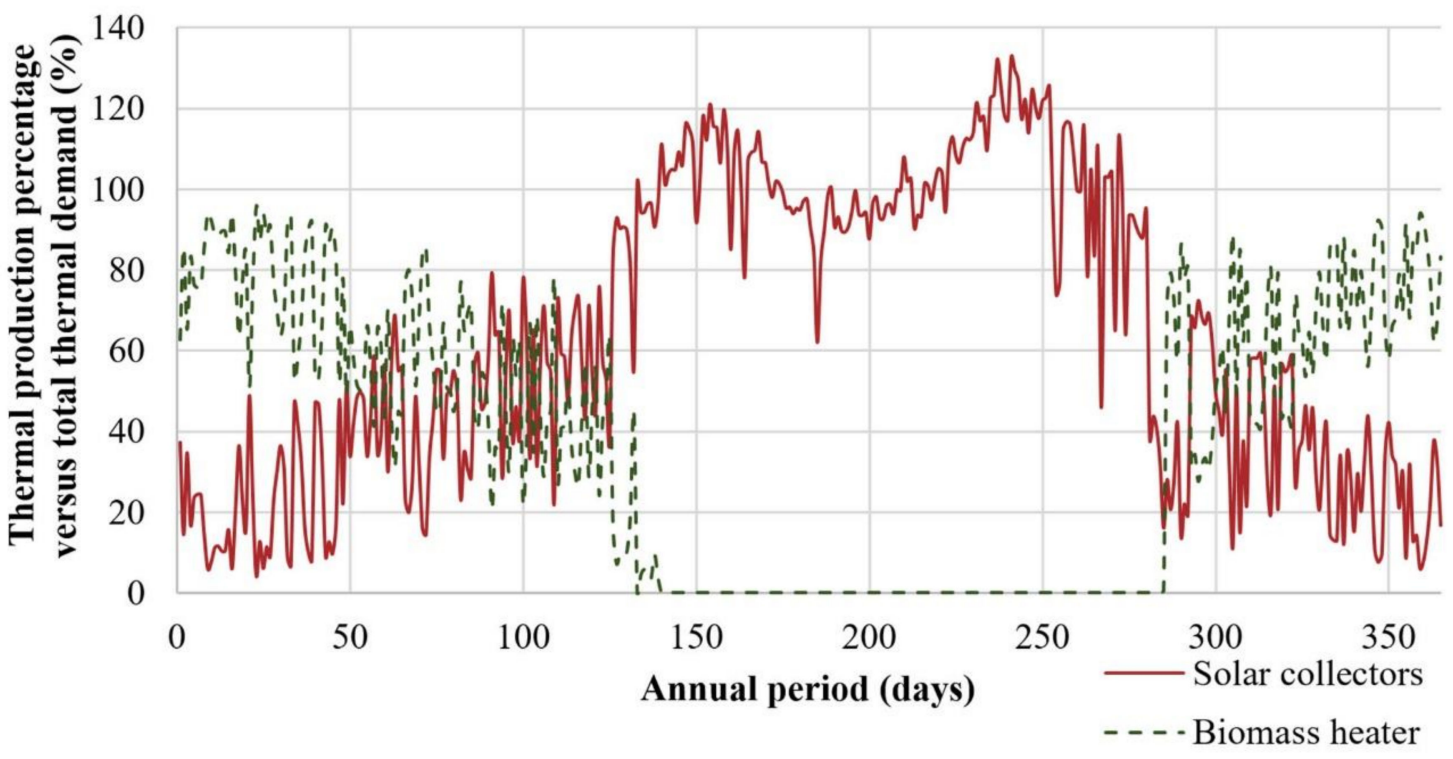

Figure 21. Annual fluctuation of the daily fractions of the solar collectors and the biomass thermal energy production versus the thermal energy demand.

\section{Conclusions}

The article aims to prove and justify the high technical and economic feasibility of the replacement of conventional thermal energy production technologies based on the consumption of diesel oil and electricity with solar-combi systems, especially for regions with high solar radiation and for large thermal energy consumptions-conditions which are often met in sports facilities.

Following the results of the work presented in this article, it can be concluded that solar-combi systems constitute an ideal option for thermal energy production for geographical regions with annual incident irradiation on horizontal plane higher than $1700 \mathrm{kWh} / \mathrm{m}^{2}$. The investment is optimized for annual thermal energy coverage from the solar collectors at the range of 50-55\% versus the total annual thermal energy demand. Depending on the procurement cost of the primary energy resources currently consumed, the payback period of the required investment can be in the range of 5 to 6 years.

Obviously, the economic feasibility of the proposed system is highly dependent on the annual fluctuation and scale of the thermal power demand. The particularly examined case in this article could be characterized as highly favorable, given the existence of significant thermal energy demand during the whole annual period, maximizing the capacity factor of the introduced solar-combi system. In cases of thermal power demand with intensive seasonality (e.g., indoor space heating), the economic feasibility of similar systems is considerably affected (indicative payback periods higher than 10 years).

If a biomass heater is utilized as the back-up unit of the solar-combi system, the total thermal energy production can be exclusively based on the exploitation of RES, leading to the elimination of any possible exhaustible energy resources currently consumed.

The massive introduction of solar-combi systems supported by biomass heaters in a geographical region can potentially trigger the development of a local biomass fuel production line. This potential can constitute an essential pillar for the support of local economies, both through the development of a new commercial activity and, maybe even most importantly, through the elimination of the consumption of imported and expensive fossil fuels for the coverage of indoor space heating and hot water production. Indicatively, it was roughly estimated that the local biomass potential in Crete-from pruning olive trees alone-could substitute more than $85 \%$ of the diesel oil currently consumed annually on the island for indoor space heating.

To conclude, solar-combi systems constitute excellent options, with strong technical and economic feasibility, especially in southern climates and in cases of considerable thermal energy needs during the 
whole annual period. They can also considerably contribute to local economies, due to their potential high added value. For all these reasons, strong economic incentives and funding tools should be provided by governments or local authorities, focusing on building capacity and the stimulation of local communities towards the involvement of solar-combi systems in their overall energy transition agenda from fossil fuels to RES.

Funding: This research was funded by MUNICIPALITY OF HERAKLION, grant number 41480/16-5-2018.

Acknowledgments: Special thanks to the Technical Service of the Pancretan Stadium for the provided support and data on the existing system's layout and the current energy consumption in the stadium, and particularly to Kalogerakis Vasilis, Konidakis Dimitris and Tsirakos Dimitris.

Conflicts of Interest: The authors declare no conflict of interest.

\section{Nomenclature}

\begin{tabular}{|c|c|c|}
\hline \multicolumn{3}{|c|}{ Data } \\
\hline Symbol & Description & Value \\
\hline$c_{w}:$ & the specific heat capacity of water & $4.180 \mathrm{~kJ} / \mathrm{kgK}$ \\
\hline$T_{h w}:$ & the hot water temperature & $45^{\circ} \mathrm{C}$ \\
\hline$T_{w s}:$ & the water temperature at the hydraulic supply network & see Table 1 \\
\hline$\rho_{h w}:$ & density of hot water at $45^{\circ} \mathrm{C}$ temperature & $990 \mathrm{~kg} / \mathrm{m}^{3}$ \\
\hline$A_{s p}:$ & the swimming pools upper surface area & $25 \times 12.5+12.5 \times 6=387.5 \mathrm{~m}^{2}$ \\
\hline$T_{\text {in }}:$ & $\begin{array}{l}\text { the swimming pools indoor space temperature according } \\
\text { to thermal comfort conditions }\end{array}$ & $\begin{array}{l}\text { in winter: } 18^{\circ} \mathrm{C} \\
\text { in summer: } 25^{\circ} \mathrm{C}\end{array}$ \\
\hline$T_{w}:$ & the desirable water temperature in the swimming pools & $\begin{array}{l}\text { main pool: } 26^{\circ} \mathrm{C} \text { training pool: } \\
30{ }^{\circ} \mathrm{C}\end{array}$ \\
\hline$h_{c}:$ & $\begin{array}{l}\text { the convective heat transfer factor for indoor space air } \\
\text { flows above horizontal surfaces }\end{array}$ & $2.5 \mathrm{~W} / \mathrm{m}^{2} \cdot \mathrm{K}$ \\
\hline$\sigma:$ & the Stefan-Boltzman constant & $5.6710^{-8} \mathrm{~W} / \mathrm{m}^{2} \cdot \mathrm{K}^{4}$ \\
\hline$\varepsilon_{w}:$ & the radiation emissivity of water & 0.957 \\
\hline$A_{c}:$ & the solar collector's effective area & $2.3 \mathrm{~m}^{2}$ \\
\hline$T_{a}:$ & the ambient temperature (in $\mathrm{K}$ ) & see Figure 9 \\
\hline$c_{p}:$ & $\begin{array}{l}\text { the specific heat capacity of the working fluid in the } \\
\text { solar collectors loop }\end{array}$ & $4.184 \mathrm{~kJ} /(\mathrm{kg} \cdot \mathrm{K})$ \\
\hline$N:$ & $\begin{array}{l}\text { the number of the collectors' protective transparent } \\
\text { top cover }\end{array}$ & 1 \\
\hline$t_{e}, t_{b}:$ & $\begin{array}{l}\text { the insulation thickness } t_{e} \text { and } t_{b} \text { in the side edges and in } \\
\text { the bottom of the solar collectors respectively }\end{array}$ & $7 \mathrm{~mm}$ \\
\hline$W:$ & $\begin{array}{l}\text { the distance between two consecutive pipelines of the } \\
\text { solar collector }\end{array}$ & $115 \mathrm{~mm}$ \\
\hline$D:$ & the solar collector's pipeline outer diameter & $11 \mathrm{~mm}$ \\
\hline$D_{i}:$ & $\begin{array}{l}\text { the solar collector's pipeline inner diameter } \\
\text { the thermal conductivity factors of the collector's }\end{array}$ & $10 \mathrm{~mm}$ \\
\hline$k_{e}, k_{b}$ & $\begin{array}{l}\text { insulation for the side edges and for the bottom of the } \\
\text { collector respectively }\end{array}$ & $0.0245 \mathrm{~W} /(\mathrm{m} \cdot \mathrm{K})$ \\
\hline$\varepsilon_{g}:$ & the emissivity of the collector's transparent cover & 0.88 \\
\hline$\varepsilon_{p}:$ & the emissivity of the collector's absorber plate & 0.95 \\
\hline$k:$ & the thermal conductivity factor of the absorber plate & $350 \mathrm{~W} /(\mathrm{m} \cdot \mathrm{K})$ \\
\hline$\delta:$ & the thickness of the absorber plate & $0.50 \mathrm{~mm}$ \\
\hline$k_{b}:$ & $\begin{array}{l}\text { the thermal conductivity factor of the bond's material of } \\
\text { the collector's pipelines with the absorber plate }\end{array}$ & $1000 \mathrm{~W} /(\mathrm{m} \cdot \mathrm{K})$ \\
\hline$b$ : & $\begin{array}{l}\text { the bond's thickness of the collector's pipelines with the } \\
\text { absorber plate }\end{array}$ & $0.60 \mathrm{~mm}$ \\
\hline$\gamma:$ & $\begin{array}{l}\text { the bond's width of the collector's pipelines with the } \\
\text { absorber plate }\end{array}$ & $0.120 \mathrm{~mm}$ \\
\hline$\beta:$ & the collector's installation angle & $45^{\circ}$ \\
\hline
\end{tabular}




\begin{tabular}{|c|c|c|}
\hline$h_{f i}:$ & $\begin{array}{l}\text { the thermal convective factor for the heat transfer from } \\
\text { the plate to the working fluid in the collectors' pipelines }\end{array}$ & $3000 \mathrm{~W} /\left(\mathrm{m}^{2} \cdot \mathrm{K}\right)$ \\
\hline$h_{e}, h_{b}:$ & $\begin{array}{l}\text { the thermal transition factors for the heat transfer from } \\
\text { the collector's side edges and bottom respectively to } \\
\text { the ambient }\end{array}$ & $10 \mathrm{~W} /\left(\mathrm{m}^{2} \cdot \mathrm{K}\right)$ \\
\hline$m:$ & $\begin{array}{l}\text { the mass flow rate of the working fluid inside the } \\
\text { collector per unit of solar collectors' effective surface. }\end{array}$ & $0.02 \mathrm{~kg} / \mathrm{s} \cdot \mathrm{m}^{2}$ \\
\hline$U_{s}:$ & $\begin{array}{l}\text { the thermal transmittance factor of the thermal } \\
\text { storage tank }\end{array}$ & 0.16 \\
\hline$A_{s}:$ & the heat transfer area of the thermal storage tank & $10.9 \mathrm{~m}^{2}$ \\
\hline$h_{w}:$ & the convective heat transfer factor of still water & $50 \mathrm{~W} /\left(\mathrm{m}^{2} \cdot \mathrm{K}\right)$ \\
\hline$k_{c}:$ & the floating insulating cover conductivity coefficient & $0.025 \mathrm{~W} /(\mathrm{m} \cdot \mathrm{K})$ \\
\hline$d_{c}:$ & the floating insulating cover thickness & $2.0 \mathrm{~cm}$ \\
\hline$m:$ & the water mass in the storage tank & $5000 \mathrm{~kg}$ \\
\hline$\varepsilon_{c}:$ & $\begin{array}{l}\text { the radiation emissivity of the insulating floating cover } \\
\text { material }\end{array}$ & 0.550 \\
\hline$t:$ & the duration of the calculation time step & $3600 \mathrm{~s}$ \\
\hline$i:$ & the discount rate & $3 \%$ \\
\hline$L:$ & the total life period of the solar-combi system & 20 years \\
\hline
\end{tabular}

\section{Symbol Description}

$Q_{h w}$ :

$Q_{s p}$ :

$Q_{\text {tot }}$ :

$Q_{d}$ :

$Q_{b}:$

$G_{t}$ :

$m_{h w}$ :

U:

the hourly average thermal power required for hot water production (in W)

the swimming pools hourly average heating load (in W)

the total thermal power production by each independent solar-combi system (in W)

the total thermal power demand (in W)

the thermal power production from the biomass heater (in $\mathrm{W}$ )

the total incident solar radiation (in $\mathrm{W} / \mathrm{m}^{2}$ )

the hourly average consumed hot water mass flow rate (in $\mathrm{kg} / \mathrm{s}$ )

the U-factor determining the heat transfer rate from the swimming pools free surface to the indoor environment (in $\mathrm{W} / \mathrm{m}^{2} \mathrm{~K}$ )

$U_{L}:$ the total thermal transmittance factor for the heat losses from solar collectors to the ambient (in $\mathrm{W} / \mathrm{m}^{2} \mathrm{~K}$ )

$U_{b}, U_{e}, U_{t}$ : the thermal transmittance factors describing the heat losses from the solar collector's bottom, side edges and top respectively to the ambient (in $\mathrm{W} / \mathrm{m}^{2} \mathrm{~K}$ )

$h_{r w}$ : the heat transfer factor with radiation from the pools free surface (in $\mathrm{W} / \mathrm{m}^{2} \mathrm{~K}$ )

$h_{t}$ : $\quad$ the thermal transition factor for the heat transfer from the collector to the ambient (in W/m $/ \mathrm{m}^{2} \mathrm{~K}$ )

$T_{\text {out }}$ : the working medium's outlet temperature of each solar-combi system (in K)

$T_{S}(i)$ : the water temperature inside the thermal storage tank at the calculation time step $\mathrm{i}$ (in $\mathrm{K}$ )

$T_{p m}$ : the solar collectors' absorber plate average temperature (in K)

$T_{f i}: \quad$ the fluid's inlet temperature in the solar collector (in K)

L.C.: $\quad$ the annually average, thermal energy production specific cost of the solar-combi system

I.C.: (in EUR/kWh)

A.O.C.: the total annual operation and maintenance cost of the solar-combi system (in EUR/year)

\section{References}

1. Cunio, L.N.; Sproul, A.B. Performance characterisation and energy savings of uncovered swimming pool solar collectors under reduced flow rate conditions. Sol. Energy 2012, 86, 1511-1517. [CrossRef]

2. Bunea, M.; Perers, B.; Eicher, S.; Hildbrand, C.; Bony, J.; Citherlet, S. Mathematical modelling of unglazed solar collectors under extreme operating conditions. Sol. Energy 2015, 118, 547-561. [CrossRef]

3. Soltau, H. Testing the thermal performance of uncovered solar collectors. Sol. Energy 1992, 49, $263-272$. [CrossRef]

4. Hashim, W.M.; Shomran, A.T.; Jurmut, H.A.; Gaaz, T.S.; Al-Amiery, A.A. Case study on solar water heating for flat plate collector. Case Stud. Therm. Eng. 2018, 12, 666-671. [CrossRef] 
5. Pandey, K.M.; Chaurasiya, R. A review on analysis and development of solar flat plate collector. Renew. Sustain. Energy Rev. 2017, 67, 641-650. [CrossRef]

6. Hao, W.; Lu, Y.; Lai, Y.; Yu, H.; Lyu, M. Research on operation strategy and performance prediction of flat plate solar collector with dual-function for drying agricultural products. Renew. Energy 2018, 127, 685-696. [CrossRef]

7. Tian, Z.; Perers, B.; Furbo, S.; Fan, J. Thermo-economic optimization of a hybrid solar district heating plant with flat plate collectors and parabolic trough collectors in series. Energy Convers. Manag. 2018, 165, 92-101. [CrossRef]

8. Nitsas, M.T.; Koronaki, I.P. Experimental and theoretical performance evaluation of evacuated tube collectors under Mediterranean climate conditions. Therm. Sci. Eng. Prog. 2018, 8, 457-469. [CrossRef]

9. Shafieian, A.; Khiadani, M.; Nosrati, A. A review of latest developments, progress, and applications of heat pipe solar collectors. Renew. Sustain. Energy Rev. 2018, 95, 273-304. [CrossRef]

10. Daghigh, R.; Shafieian, A. Theoretical and experimental analysis of thermal performance of a solar water heating system with evacuated tube heat pipe collector. Appl. Therm. Eng. 2016, 103, 1219-1227. [CrossRef]

11. Sabiha, M.A.; Saidur, R.; Mekhilef, S.; Mahian, O. Progress and latest developments of evacuated tube solar collectors. Renew. Sustain. Energy Rev. 2015, 51, 1038-1054. [CrossRef]

12. Lamnatou, C.; Cristofari, C.; Chemisana, D.; Canaletti, J.L. Building-integrated solar thermal systems based on vacuum-tube technology: Critical factors focusing on life-cycle environmental profile. Renew. Sustain. Energy Rev. 2016, 65, 1199-1215. [CrossRef]

13. Hassanien, R.; Hassanien, E.; Li, M.; Tang, Y. The evacuated tube solar collector assisted heat pump for heating greenhouses. Energy Build. 2018, 169, 305-318. [CrossRef]

14. Shafii, M.B.; Mamouri, S.J.; Lotfi, M.M.; Mosleh, H.J. A modified solar desalination system using evacuated tube collector. Desalination 2016, 396, 30-38. [CrossRef]

15. Tyagi, V.V.; Kaushik, S.C.; Tyagi, S.K. Advancement in solar photovoltaic/thermal (PV/T) hybrid collector technology. Renew. Sustain. Energy Rev. 2012, 16, 1383-1398. [CrossRef]

16. Abdelrazik, A.S.; Al-Sulaiman, F.A.; Saidur, R.; Ben-Mansour, R. A review on recent development for the design and packaging of hybrid photovoltaic/thermal (PV/T) solar systems. Renew. Sustain. Energy Rev. 2018, 95, 110-129. [CrossRef]

17. Parvez Mahmud, M.A.; Huda, N.; Farjana, S.H.; Lang, C. Environmental impacts of solar-photovoltaic and solar-thermal systems with life-cycle assessment. Energies 2018, 11, 2346. [CrossRef]

18. Ruan, Y.; Liu, Q.; Li, Z.; Wu, J. Optimization and analysis of building combined cooling, heating and power (BCHP) plants with chilled ice thermal storage system. Appl. Energy 2016, 179, 738-754. [CrossRef]

19. Murugan, S.; Horák, B. A review of micro combined heat and power systems for residential applications. Renew. Sustain. Energy Rev. 2016, 64, 144-162. [CrossRef]

20. Huang, Y.; McIlveen-Wright, D.R.; Rezvani, S.; Huang, M.J.; Wang, Y.D.; Roskilly, A.P.; Hewitt, N.J. Comparative techno-economic analysis of biomass fuelled combined heat and power for commercial buildings. Appl. Energy 2013, 112, 518-525. [CrossRef]

21. Molavi, J.; McDaniel, J. A Review of the benefits of geothermal heat pump systems in retail buildings. Procedia Eng. 2016, 145, 1135-1143. [CrossRef]

22. Eicker, U.; Vorschulze, C. Potential of geothermal heat exchangers for office building climatisation. Renew. Energy 2009, 34, 1126-1133. [CrossRef]

23. Pahud, D.; Belliardi, M.; Caputo, P. Geocooling potential of borehole heat exchangers' systems applied to low energy office buildings. Renew. Energy 2012, 45, 197-204. [CrossRef]

24. Moià-Pol, A.; Pujol-Nadal, R.; Martínez-Moll, V.; Hertel, J.D. Retrofit of a solar system in sport center in Mallorca. Energy Procedia 2016, 91, 190-196. [CrossRef]

25. Artuso, P.; Santiangeli, A. Energy solutions for sports facilities. Int. J. Hydrog. Energy 2008, 33, $3182-3187$. [CrossRef]

26. Zuccari, F.; Santiangeli, A.; Orecchini, F. Energy analysis of swimming pools for sports activities: Cost effective solutions for efficiency improvement. Energy Procedia 2017, 126, 123-130. [CrossRef]

27. Katsaprakakis, D.A. Comparison of swimming pools alternative passive and active heating systems based on renewable energy sources in Southern Europe. Energy 2015, 81, 738-753. [CrossRef]

28. Kaci, K.; Merzouk, M.; Kasbadji Merzouk, N.; El Ganaoui, M.; Sami, S.; Djedjig, R. Dynamic simulation of hybrid-solar water heated olympic swimming pool. Energy Procedia 2017, 139, 750-757. [CrossRef] 
29. Starke, A.R.; Cardemil, J.M.; Colle, S. Multi-objective optimization of a solar-assisted heat pump for swimming pool heating using genetic algorithm. Appl. Therm. Eng. 2018, 142, 118-126. [CrossRef]

30. Barbato, M.; Cirillo, L.; Menditto, L.; Moretti, R.; Nardini, S. Feasibility study of a geothermal energy system for indoor swimming pool in Campi Flegrei area. Therm. Sci. Eng. Prog. 2018, 6, 421-425. [CrossRef]

31. Katsaprakakis, D.A.; Dakanali, I.; Zidianakis, G.; Yiannakoudakis, Y.; Psarras, N.; Kanouras, S. Potential on energy performance upgrade of national stadiums: a case study for the Pancretan stadium, Crete, Greece. Appl. Sci. 2019, 9, 1544. [CrossRef]

32. Directive on Buildings' Energy Performance. Official Governmental Gazette 2367B'/12-7-2017. Available online: http://tdm.tee.gr/wp-content/uploads/2017/07/fek_12_7_2017_egrisi_kenak.pdf (accessed on 21 February 2020).

33. 2009 ASHRAE Handbook-Fundamentals (SI Edition); American Society of Heating, Refrigerating and Air-Conditioning Engineers, Inc.: Atlanta, GA, USA, 2009.

34. Kreider, J.; Rabl, A.; Curtiss, P. Heating and Cooling of Buildings, 3rd ed.; CRC Press: Boca Raton, FL, USA, 2017.

35. Katsaprakakis, D.A.; Zidianakis, G. Optimized dimensioning and operation automation for a solar-combi system for indoor space heating. A case study for a school building in Crete. Energies 2019, 12, 177. [CrossRef]

36. Kefalloniti, I.; Ampatzi, E. Building integration of domestic solar combi-systems: The importance of managing the distribution pipework. Energy Build. 2017, 142, 179-190. [CrossRef]

37. Glembin, J.; Haselhorst, T.; Steinweg, J.; Rockendorf, G. Simulation and evaluation of solar thermal combi systems with direct integration of solar heat into the space heating loop. Energy Procedia 2016, 91, 450-459. [CrossRef]

38. Antoniadis, C.N.; Martinopoulos, G. Simulation of solar thermal systems with seasonal storage operation for residential scale applications. Procedia Environ. Sci. 2017, 38, 405-412. [CrossRef]

39. Yang, Z.; Wang, Y.; Li, X. Building space heating with a solar-assisted heat pump using roof-integrated solar collectors. Energies 2011, 4, 504-516. [CrossRef]

40. Kalder, J.; Annuk, A.; Allik, A.; Kokin, E. Increasing solar energy usage for dwelling heating, using solar collectors and medium sized vacuum insulated storage tank. Energies 2018, 11, 1832. [CrossRef]

41. Katsaprakakis, D.A.; Zidianakis, G. Upgrading energy efficiency for school buildings in Greece. Procedia Environ. Sci. 2017, 38, 248-255. [CrossRef]

42. Kyriaki, E.; Giama, E.; Papadopoulou, A.; Drosou, V.; Papadopoulos, A.M. Energy and environmental performance of solar thermal systems in hotel buildings. Procedia Environ. Sci. 2017, 38, 36-43. [CrossRef]

43. Calise, F.; Figaj, R.D.; Vanoli, L. Energy and economic analysis of energy savings measures in a swimming pool centre by means of dynamic simulations. Energies 2018, 11, 2182. [CrossRef]

44. Hsieh, S.; Omu, A.; Orehounig, K. Comparison of solar thermal systems with storage: From building to neighbourhood scale. Energy Build. 2017, 152, 359-372. [CrossRef]

45. Tirumala, N.; Kumar, U.; Martin, A.R. Co-production performance evaluation of a novel solar combi system for simultaneous pure water and hot water supply in urban households of UAE. Energies 2017, 10, 481.

46. Bois, J.; Mora, L.; Wurtz, E. Energy saving analysis of a solar combi-system using detailed control algorithm modeled with modelica. Energy Procedia 2015, 78, 1985-1990. [CrossRef]

47. Deng, S.; Dai, Y.J.; Wang, R.Z. Performance optimization and analysis of solar combi-system with carbon dioxide heat pump. Sol. Energy 2013, 98, 212-225. [CrossRef]

48. D'Antoni, M.; Ferruzzi, G.; Bettoni, D.; Fedrizzi, R. Validation of the numerical model of a turnkey solar combi + system. Energy Procedia 2012, 30, 551-561. [CrossRef]

49. Johansen, J.B.; Englmair, G.; Dannemand, M.; Kong, W.; Furbo, S. Laboratory testing of solar combi system with compact long term PCM heat storage. Energy Procedia 2016, 91, 330-337. [CrossRef]

50. Englmair, G.; Dannemand, M.; Johansen, J.B.; Kong, W.; Dragsted, J.; Furbo, S.; Fan, J. Testing of PCM heat storage modules with solar collectors as heat source. Energy Procedia 2016, 91, 138-144. [CrossRef]

51. Colclough, S.; McGrath, T. Net energy analysis of a solar combi system with seasonal thermal energy store. Appl. Energy 2015, 147, 611-616. [CrossRef]

52. Ma, Z.; Bao, H.; Roskilly, A.P. Feasibility study of seasonal solar thermal energy storage in domestic dwellings in the UK. Sol. Energy 2018, 162, 489-499. [CrossRef]

53. Andersen, E.; Furbo, S. Theoretical variations of the thermal performance of different solar collectors and solar combi systems as function of the varying yearly weather conditions in Denmark. Sol. Energy 2009, 83, 552-565. [CrossRef] 
54. Mauthner, F.; Weiss, W.; Spörk-Dür, M. Solar Heat Worldwide: Markets and Contribution to the Energy Supply 2014. AEE-Institute for Sustainable Technologies, A-8200 Gleisdorf, Austria. IEA Solar Heating \& Cooling Programme, May 2016. Available online: http://www.iea-shc.org/data/sites/1/publications/solarheat-worldwide-2016.pdf (accessed on 21 February 2020).

55. Wikipedia: Tichelmann-System. Available online: https://de.wikipedia.org/wiki/Tichelmann-System (accessed on 21 February 2020).

56. Duffie, J.A.; Beckman, W.A. Solar Engineering of Thermal Processes, 4th ed.; Wiley: Hoboken, NJ, USA, 2017.

(C) 2020 by the author. Licensee MDPI, Basel, Switzerland. This article is an open access article distributed under the terms and conditions of the Creative Commons Attribution (CC BY) license (http://creativecommons.org/licenses/by/4.0/). 